NBER WORKING PAPER SERIES

\title{
ONE FUNDAMENTAL AND TWO TAXES: WHEN DOES A TOBIN TAX REDUCE FINANCIAL PRICE VOLATILITY?
}

\author{
Yongheng Deng \\ Xin Liu \\ Shang-Jin Wei \\ Working Paper 19974 \\ http://www.nber.org/papers/w19974
}

\author{
NATIONAL BUREAU OF ECONOMIC RESEARCH \\ 1050 Massachusetts Avenue \\ Cambridge, MA 02138 \\ March 2014
}

We thank Geert Bekaert, Charles Jones, Wei Xiong, and participants in seminars at Columbia University, UCLA Anderson School, University of Hong Kong, the World Bank finance group, the Federal Reserve Bank of San Francisco, and the 2013 Econometric Society Far Eastern meeting in Singapore for helpful comments, and Ellen Lin and Joy Glazener for proofreading. All errors are our responsibilities. The views expressed herein are those of the authors and do not necessarily reflect the views of the National Bureau of Economic Research.

NBER working papers are circulated for discussion and comment purposes. They have not been peerreviewed or been subject to the review by the NBER Board of Directors that accompanies official NBER publications.

(C) 2014 by Yongheng Deng, Xin Liu, and Shang-Jin Wei. All rights reserved. Short sections of text, not to exceed two paragraphs, may be quoted without explicit permission provided that full credit, including $\odot$ notice, is given to the source. 
One Fundamental and Two Taxes: When Does a Tobin Tax Reduce Financial Price Volatility? Yongheng Deng, Xin Liu, and Shang-Jin Wei

NBER Working Paper No. 19974

March 2014

JEL No. G1,G14

\begin{abstract}
$\underline{\text { ABSTRACT }}$
We aim to make two contributions to the literature on the effects of transaction costs on financial price volatility. First, by using a research design with three ingredients (a common set of companies simultaneously listed on two stock exchanges; binding capital controls; different timing of changes in transaction costs), we obtain a control group that has identical corporate fundamentals as the treatment group and is therefore far cleaner than any in the existing literature. We apply the research design to Chinese stocks that are cross-listed in Hong Kong and Mainland. Second, we entertain the possibility that a given transaction cost can have different effects in immature and mature markets. In an immature market where trading is dominated by retail investors with little knowledge of accounting and finance, a Tobin tax should have the best chance of generating its intended effect. In a more mature market, higher transaction costs may also discourage sophisticated investors, hence impeding timely incorporation of fundamental information into prices. We find a significantly negative relation in the Chinese market, on average, between stamp duty increase and price volatility. However, this average effect masks some important heterogeneity. In particular, when institutional investors have become a significant part of traders' pool, we find an opposite effect. This suggests that a Tobin tax may work in an immature market but can backfire in a more developed market.
\end{abstract}

\author{
Yongheng Deng \\ Institute of Real Estate Studies \\ National University of Singapore \\ Singapore \\ ydeng@nus.edu.sg \\ Xin Liu \\ National University of Singapore \\ Kent Ridge Road \\ Republic of Singapore \\ liux@ nus.edu.sg
}

\author{
Shang-Jin Wei \\ Graduate School of Business \\ Columbia University \\ Uris Hall 619 \\ 3022 Broadway \\ New York, NY 10027-6902 \\ and NBER \\ shangjin.wei@columbia.edu
}




\section{Introduction}

One of the Economics Nobel Prize recipients in 2013 (Robert Shiller) is known for his pioneering work that questions whether financial prices are excessively volatile. The possibility of excessive volatility has motivated some to advocate the use of a transaction tax to dampen short-term speculation and to reduce such volatility. Prominent proponents of such an approach include Tobin (1978, 1984), Stiglitz (1989), and Summers and Summers (1989). In contrast, opponents argue that security transaction taxes (also known as a Tobin tax) could discourage fundamental-based traders more than they do noise traders, resulting in higher, not lower, volatility in the financial market (e.g. Grundfest (1990), Grundfest and Shoven (1991), and Kupiec (1996)). Interestingly, a large number of empirical papers that have investigated this question have not resolved this debate because some find a negative effect while others find a positive effect, and the conclusions do not appear to be converging in more recent publications.

We aim to make two main contributions to research on the effect of transaction taxes on price volatility. The first is methodological in nature; we argue that our research design offers us much sharper identification than any on the topic in the literature. One key challenge for event studies is to have a proper counterfactual: what would have happened to price volatility had the transaction tax not changed? Some of the papers in the literature use a before-and-after analysis, with the implicit assumption that the "before" scenario is the right counterfactual. This is vulnerable to the problem of confounding effects from other factors that may change market volatility for reasons unrelated to transaction costs. The best papers in the literature use a double difference research design with a treatment and a control group together with a before-and-after comparison. But the control and treatment group are not identical. Even if one can verify that the two groups are similar on observable dimensions, one cannot rule out the possibility that the two are different on unobserved dimensions in ways that could cause them to move differently around the event dates. For example, the paper with the best publication outlet on the topic is Jones and Seguin (1997) in the American Economic Review, which studies the event of a sharp reduction in the commission fee in 1975 for stocks traded on the NYSE/AMEX (their treatment group). Their control group is the set of stocks traded on NASDAQ. The control and treatment groups are similar in many dimensions but not 
identical, and their volatility could in principle move in different directions for unobserved reasons that are not related to the transaction cost event itself. This possibility cannot be easily checked especially when only a single event is studied in the paper.

Our research design has three key ingredients. (A) The treatment and control groups are the same set of firms with identical corporate fundamentals (i.e., identical dividend flows and voting rights) but are simultaneously listed on two separate stock exchanges. (B) Binding capital controls exist that prevent arbitrage activities from closing the gap between the price movements in the two markets ${ }^{1}$. (C) There are different timings of changes in the transaction costs in the two markets. The combination of the three ingredients offers sharp identification for the relationship between changes in the tax and changes in the volatility. To our knowledge, this is the first paper that uses this research design to study this question.

We apply this research design to a sample of Chinese stocks that are simultaneously listed in Mainland China and Hong Kong and thus face different transaction costs. The treatment group is the Mainland listed shares (known as A shares), and the control group is their corresponding Hong Kong listed shares (known as $\mathrm{H}$ shares). The treatment and control groups share identical corporate fundamentals as they have identical cash flow and control rights. Due to Chinese capital controls, the two markets are segmented. In particular, only Chinese residents can register a stock account to trade A shares listed on the Mainland exchanges. Foreign exchange controls during the sample period means it is not practical for Mainland residents to buy or sell H shares in Hong Kong. Even though Hong Kong does not practice capital controls, Chinese capital controls prevent Hong Kong residents (and international investors in general) from buying and selling A shares listed in the Mainland. One clear sign of the binding capital controls and segmentation of the two stock markets is the price disparity of the same companies in the two stock exchanges. Hong Kong listed $\mathrm{H}$ shares are often traded at a discount relative to their Siamese twins listed in the Mainland (see Fernald and Rogers (2002) for a documentation of the evidence and an explanation). Of course, the pools of investors in the two markets are different and the transaction costs faced by the two sets of investors are also different.

\footnotetext{
${ }^{1}$ For example, stocks cross-listed in New York and London cannot be used as valid treatment and control groups for this research question. Without binding capital controls, arbitrage would limit the range of disparity in price volatility of the same firms across markets.
} 
Our methodology does not require the two sets of investors to have identical characteristics. Indeed, they can be different in many ways. What we need is that during a narrow window before and after a change in the stamp duty, the characteristics of the pool of investors do not change except for what may be induced by the change in the stamp duty. While the stamp duty is always low and changes are negligible in Hong Kong, China has made several large adjustments in the stamp duty, which are very helpful to our identification.

The second contribution of the paper is to entertain the possibility that the effect of a given change in transaction taxes on price volatility can depend on the sophistication of the financial market or the level of financial development. The desirability of a Tobin tax is not a yes-or-no judgment, but is context-dependent. In immature or "frontier" markets, trading tends to be dominated by unsophisticated investors with little basic finance or accounting knowledge and driven by non-fundamental noises. If a Tobin tax has any hope of curbing excessive volatility, one should find it in such markets. On the other hand, in more mature markets, enough investors are sophisticated in terms of understanding the fundamentals, as represented by professional managers from pension funds, mutual funds, and hedge funds. As opponents to the Tobin tax would argue, higher transaction costs may discourage these arguably better informed investors from trading, impeding or slowing down the process of incorporating fundamental information into financial prices, and thus potentially resulting in higher, not lower, price volatility. Given the speed of financial development, two decades of the Chinese stock market development resemble two centuries of development of some developed economies on some important dimensions. In particular, institutional investors were negligible in China either in absolute numbers or as a share of market turnovers from the founding of the stock exchange in 1990 to mid-2000s. The Chinese stock market was essentially a “frontier” market, similar to 40 or so other frontier or early-stage emerging markets in the world, where trading was dominated by retail investors with little knowledge of accounting and finance. Since the late 2000s, however, there has been an explosion in the number of institutional investors. By 2012, the share of institutional investors in the market capitalization was around $55 \%{ }^{2}$, which is comparable to the level in the United

\footnotetext{
${ }^{2}$ Calculated from the WIND and the CSMAR data.
} 
States. By 2013, the institutional ownership for stocks in FTSE China Index was 36\%, which is higher than many high-income countries, such as Japan (20\%), Germany (34\%), France (30\%), Australia (24\%), and Singapore (19\%). This allows us to do something else that is unique in the literature, namely, to check if the effect of higher transaction costs on price volatility changes with a shift in market characteristics. With a changing ratio of noise traders and fundamental-based traders, a given change in the stamp duty may produce different effects on the price volatility. This evolutionary or regimedependent perspective can potentially provide a way to reconcile some of the conflicting empirical findings in the empirical literature.

There are two key findings in the paper. First, pooling over the seven discrete changes in the stamp duty, we find a negative relationship between transaction tax and price volatility, contrary to the influential papers by Jones and Seguin (1997) and Umlauf (1993). We interpreted it as evidence that a Tobin tax may achieve its intended objective in an immature market where retail investors dominate. However, this is not the end of the story. Second, we find that, with a significant presence of institutional investors, the effect of a higher transaction cost is reversed. In particular, for the two most recent changes in transaction costs (a decrease in April, 2008, and another decrease in September 2008) when the share of institutional ownership in Chinese stocks was closer to the level in the United States in the early 1970s, higher transaction costs are associated with higher price volatility. Also, across individual stocks, higher transaction costs are more likely to be positively related to volatility for stocks with a relatively high institutional trading but negatively related to volatility for stocks with relatively low or no institutional trading. This result might provide a way to reconcile some of the seemingly contradictory findings in the existing empirical literature.

Note that our interpretation does not require all institutional investors to be fundamental-based or all retail investors to be noise traders. We need only a weaker assumption which is that institutional investors are more likely to be fundamental based than retail investors. This appears highly likely as virtually all portfolio managers in China have an advanced degree in either economics or finance with systematic training in finance and accounting. 
The rest of the paper is organized as follows. Section 2 supplies some background information. Section 3 describes the data and descriptive statistics. Section 4 provides the statistical analysis. Section 5 concludes.

\section{Background Information}

In this section, we provide two types of background information. First, we briefly review the existing theoretical and empirical literatures, highlighting the design of control and treatment groups as well as the main findings. We then present some basic background about the Chinese and Hong Kong stock exchanges and the seven discrete events of stamp duty changes in Mainland China.

\subsection{The battle of ideas in the theory}

Proponents and opponents of a Tobin tax have a different market setting in mind in the theories. For proponents (Tobin, 1978 and 1984; Stiglitz, 1989; and Summers and Summers, 1989), there are many non-fundamental based traders in the market whose actions drive a wedge between the market price and the fundamental value of the underlying asset. In that case, an increase in transaction costs, by inducing these traders to trade less, especially to trade less on a short-term basis, can reduce the noise-tofundamental ratio in market prices.

For opponents to a Tobin tax idea, the effect of transaction tax on volatility is ambiguous and under some scenarios could be positive. (see Grundfest, 1990; Grundfest and Shoven, 1991;Edwards, 1993; Schwert and Seguin, 1993; and Kupiec, 1996). The market is occupied by a sufficient number of rational, fundamental traders whose trading could stabilize the market by moving prices towards true underlying values. Noise traders exist but the impact of their actions is limited by the arbitrage activities of fundamentalbased traders. An increase in transaction costs would indiscriminately discourage market participation by both types of traders. Any potentially beneficial effects on financial market from less noise trading could be partially or fully offset by a reduction in trading activities by price-stabilizing, fundamental-based traders. Song and Zhang (2005) highlight such effect by arguing that the net effect a transaction tax on volatility will depend on the composition of traders. In other words, when a given fundamental trader 
is discouraged from trading, or when fewer fundamental traders participate, the noise-tofundamental ratio could rise rather than fall ${ }^{3}$, resulting in an increases rather than a decrease in volatility. Moreover, Heaton and Lo (1995) point out that a transaction tax may increase market volatility due to reduction in market liquidity, which makes a given trade to have a larger price impact.

The ability of rational, fundamental traders to eliminate mispricing caused by noise traders has been called into question by the theory of limits of arbitrage (Shleifer and Vishny, 1997; Shleifer, 2000; and Gromb and Vayanos, 2002). On the one hand, if the limits of arbitrage are caused by risk (both fundamental and non-fundamental) or limited capital, one might think that observed market volatility is excessive and an increase in transaction costs can reduce volatility. On the other hand, if the limits of arbitrage are primarily caused by transaction costs themselves, any additional increase in transaction costs could further constrain the capacity of rational traders and hence lead to a rise in the price volatility (see Gromb and Vayanos, 2010, for a recent survey of the literature on limits of arbitrage). We are not aware of theoretical work that formally investigates the net effect of these competing forces in the context of Tobin taxes and financial price volatility.

\subsection{Existing empirical literature}

Our study with unique A-H twin shares as treatment-control pairs contributes to the literature with an improved understanding of the Tobin tax. Only a few studies find empirical evidence supporting the proponent's view of securities transaction taxes (STT). Liu and Zhu (2009) find that commission deregulation in Japan is associated with a statistically and economically significant increase in price volatility, which suggests that imposing higher transaction costs might be feasible to stabilize the market by curbing short-term noise trading. Hanke et al. (2010) also show evidence to support that a Tobin tax would reduce speculative trading. However, neither study uses a control group that

\footnotetext{
${ }^{3}$ When security trading can take place in multiple locations, non-coordinated changes in transaction costs can cause trading to migrate from a higher tax location to a lower tax one. We do not study this feature in our paper. Trading in our sample cannot migrate from one market to the other due to binding capital controls.
} 
can be said to be the same as the treatment group. Moreover, since more studies ${ }^{4}$ find the opposite effect of STT on price volatility, this paper contributes to the literature by providing a potential explanation for the inconsistencies in empirical evidences. Umlauf (1993) studies the volatility impact of the inception and increase of a Swedish tax and finds that volatility significantly increased in response to the introduction of taxes although stock price levels and turnover declined. Jones and Seguin (1997) find consistent results with Umlauf (1993) that a reduction in transaction costs is associated with a decline in price volatility. They argue that increasing the costs of trading through transaction taxes, increasing margin requirements, or reducing the availability of low-cost substitutes like equity futures may in fact encourage, rather than reduce the impact of noise traders and volatility. In addition, findings of no significant impact of STT on market volatility cast doubt on STT as an effective policy instrument. Roll (1989) uses cross-country data to study the matter and finds that transaction taxes are inversely but insignificantly correlated with market volatility. Hu (1998) finds with Asian market data that increases in STT reduce the stock price, but have no significant impact on price volatility or turnover.

Lastly, our study has broad implications for other security classes. Several researchers study the question with the housing market instead. Fu et al. (2012) use the Singapore housing market data and show that prices become less informative and volatility significantly increases in the affected market following the transaction tax increase. Sheffrin and Turner (2001) find a capital gains tax with full loss offset at ordinary tax rates would generate a benefit to households by reducing the volatility of housing returns; however, the effect on the rate of return exceeds the benefits of volatility reduction. Aregger et al. (2012) show that transaction taxes have no impact on house price growth based on evidence from the variation of tax rates across Swiss cantons, while capital gains taxes exacerbate house price dynamics. Note in all these studies, the treatment and control groups are the same set of housing assets.

As we restrict our attention to domestic securities markets, we ignore international dimensions of the issue. When the trading of a given financial asset can be chosen from a

\footnotetext{
${ }^{4}$ See e.g. Hau (2006), Habemeier and Kirilenko (2001), Lanne and Vesala (2010), Aliber, et al. (2002), Chuo and Wang (2006), Green, Maggioni and Murinde (2000), Atkins and Dyl (1997), and Westerhold (2003), Baltagi et al. (2006), and Phylakti and Aristidou (2007).
} 
menu of locations, the effect of a Tobin tax can be further limited if coordination across the locations is difficult or infeasible.

\subsection{Stamp Duties in the Chinese Stock Market}

The history of the stock trading stamp duty in China goes back to the early 90s, shortly after the establishment of the two stock exchanges in Shenzhen and Shanghai, respectively. While there were three adjustments in the duty during 1990-1992, there was no cross listed stock at the time. So these adjustments are not part of our sample.

The stamp duty is regarded by the Ministry of Finance as a revenue-generating tool. After 1992, the year in which the China Securities Regulatory Commission (CSRC) was established, a surge in the stock market transaction volume made stamp duty a noticeable source of revenue. While at the beginning, the revenue was shared 50-50 between the Ministry of Finance and local governments, the sharing rule has been adjusted a few times, progressively more in favor of the central government. After 2002, $97 \%$ of the stamp duty revenue has been accrued to the central government. The dominance of the revenue consideration makes it plausible that adjustments in the stamp duty are not an endogenous response to changes in stock price volatility.

As shown in Table 1 and Figure 1, there are seven adjustments in stock trading stamp duty during the sample period. After an increase in stamp duty in 1997, the duty was adjusted downwards three times between 1998 and 2007, but raised again in 2007, before two more downwards adjustments in 2008.

The historical stamp duty adjustments in the Hong Kong Stock Exchange (HKEX) are also reported in Table 1 (and Figure 1). Not only is the level of the stamp duty in Hong Kong low, the magnitudes of the adjustments are almost negligible when compared to the A-share market. In any case, the duty stays at a low constant level of 1\%o of transaction value for buyer and seller after 2001. In our statistical analysis, we will ignore the adjustments in the stamp duties in Hong Kong. If the small changes in the Hong Kong duty are not systematically related to the changes in the Mainland ${ }^{5}$, they are essentially noises in our analysis, and make it harder for us to find statistically significant effects.

\footnotetext{
${ }^{5}$ The correlation in the monthly changes in the stamp duty between the Hong Kong and Mainland Chinese markets is -0.006 .
} 


\subsection{A short history of institutional investors in China}

The Chinese stock market, for much of its 20-plus-year history, is known to be dominated by retail investors. Figure 2 provides a graphical illustration of the evolution of institutional investors in China based on the quarterly institutional holding information from the WIND database. First, Figure 2a shows the time series of outstanding institutional investors in the Chinese domestic stock market. Next, Figure $2 b$ shows the shares of institutional holdings in the Chinese A-share market and the US market, respectively. In 1975, the year of the event studied by Jones and Seguin (1997), the share of institutional holding in the United States reached about 22\%. China did not reach this level until 2008. (Both the number of institutional investors and the share of institutional holdings have exploded since 2008, though the stamp duty in the A-share market stays at a low level of $0.1 \%$ which was set in September 2008.)

It is convenient to think of the history of Chinese institutional investors in three stages. First, in an infant stage between 1990 and 1997, the financial market is overwhelmingly populated by retail investors, whereas institutional investors were negligible both in numbers and in trading volume. In the second stage - a toddler stage from 1998 to 2005, mutual funds and insurance companies, and to a smaller degree, pension funds and hedge funds, began to emerge in the Chinese stock market. Finally, since 2006, a growth stage sets in when institutional investors have grown at a high speed, eventually catching up with the U.S. level by 2012 in terms of its relative importance in both trading and shareholding.

\section{Empirical Results}

\subsection{Data}

Since the two Chinese stock exchanges were established in 1990 and 1991, respectively, the government has implemented ten adjustments to the stamp duty. The first three took place during 1990-1992, before there were any cross-listed Chinese stocks. As a result, our sample covers the last seven changes in the stamp duties, which took

place during 1996-2009. The stamp duty during our sample period was set jointly by the Ministry of Finance and the China Securities Regulatory Commission, and was always 
applied to stock trading on both the Shanghai and Shenzhen stock exchanges. The changes in the stamp duty are both listed in Table 1 and graphed in Figure 1. While there are also independent changes in the stamp duties in Hong Kong, the changes are negligibly small when compared to the changes in the Mainland. The comparison can be most clearly seen in Figure 1. In this paper, we will ignore stamp duty changes in Hong Kong. Because the changes in Hong Kong are not systematically related to those in the Mainland (and are very small anyway), they mainly add noise to our inferences.

Our sample of stocks consists of the universe of 53 Chinese companies that are crosslisted in both Mainland China and Hong Kong. Because the last stamp duty event took place in September 2008, stocks that become cross-listed after 2008 do not make it into our sample. Appendix 1 provides a list of these companies in the sample and their IPO dates on both stock exchanges, sorted by the date they first became cross-listed.

Because the number of cross-listed stocks increases gradually during the sample period, the total number of unique firm-event observations is 223 , less than $7 \times 53$. Daily information of $\mathrm{A}$ and $\mathrm{H}$ shares comes from the China Securities Market and Accounting Research Database (CSMAR), Reuters Datastream and the Pacific Basin Capital Market Database (PACAP).

The summary statistics of our sample is reported in Table 2. In panel A, we first show the mean and median of firm characteristics of our cross-listed sample and the entire Ashare market for 1996 and 2008 respectively. Firm financials are obtained from CSMAR and institutional ownership information is from WIND, which reflects the values of the latest annual or quarter filing of the year. A few remarks are in order. First, there is a dramatic growth in market and firm size from 1996 to 2008. Second, for both 1996 and 2008, cross-listed firms are significantly larger than the market average in terms of total assets and sales. Interestingly, we see that cross-listed firms are less profitable than the market average in 1996 in terms of EBIT/sales and net margin. However, the opposite effect is seen in 2008: cross-listed firms are on average more profitable than the market average. Consistently, cross-listed firms have higher leverage than the market average, highlighting their advantage in accessing debt financing. Lastly, beside the dramatic growth in the fraction of ownership held by institutional investors, cross-listed firms are 
higher on average in terms of institutional holdings, institutional turnover, and the number of institutional investors at the firm level.

Panel B provides the stock characteristics of $\mathrm{A}$ and $\mathrm{H}$ shares, respectively. The average market capitalization of A-share stocks in our sample is RMB127 billion, while the corresponding value of $\mathrm{H}$-share stocks is about RMB37 billion ${ }^{6}$, suggesting that domestic A-share serves as the primary market for these Chinese firms. It is easy to see that the capital controls that produce the segmentation of the Hong Kong and Mainland China stock markets are binding: H-share stocks see a $50 \%$ discount in stock price relative to the A-share stocks. Although daily transaction volume and price volatility are comparable, A-share is more liquid as suggested by the Amihud illiquidity ratio.

For each cross-listed stock, we compute its separate volatilities, averaged over the entire sample period, in the $\mathrm{A}$ and $\mathrm{H}$ markets, respectively. Figure 4 plots the A-share volatility against its H-share counterpart across the 53 stocks. There is a visibly positive correlation between the two, which should not be too surprising.

Table 3 provides the correlation matrix of our key variables. The correlation between A-share and $\mathrm{H}$-share returns is 0.35 , while the correlation in price volatility between the A and $\mathrm{H}$ markets is 0.27 .

\subsection{Price Response to Stamp Duty Changes}

We start with examining the short-term price response of cross-listed A-H shares around stamp duty changes. However, as Schwert and Seguin (1993) point out, the effect of STT on stock price could go either way. First, suppose imposing a transaction tax could effectively reduce excessive volatility and thus reduce risk borne by investors, the risk premium of stocks should go down. Since investors now require a lower rate of returns and cash flows are now discounted at a lower rate, share prices should go up. On the other hand, STT could also lower stock price as transaction costs generally diminish investors' incentive to trade unless the projected profit is higher than the transaction cost. Therefore, it raises investors' required rate of return for trading and puts downward pressure on stock price. This discussion means that the net effect of higher transaction

\footnotetext{
${ }^{6}$ We convert the HKD to RMB with historical daily exchange rates at each trading date.
} 
costs on stock prices depends on the relative strength of the two forces and is theoretically ambiguous.

To examine this in the context of the stamp duty in China, a difference-in-differences regression is adopted in the paper, and daily stock returns from two trading days before to two trading days after each stamp duty change are tested as following:

$$
R_{m, i, t}^{T}=\gamma_{0}+\gamma_{1} R_{m, i, t}^{C}+\gamma_{2} R_{m, i, t}^{C} H_{i g h e r} t_{-} x_{-} d u m m y_{m, i, t}+F+\varepsilon_{m, i, t}
$$

$R_{m, i, t}^{T}$ and $R_{m, i, t}^{C}$ are the daily returns of the treatment and control shares respectively, and higher_tax_dummy equals to one if day $t$ is in the higher stamp duty period and zero otherwise. For example, for an upward adjustment in the stamp duty, the observations after the event date will be classified as with higher tax, and vice versa. Also, $F$ reflects a collection of fixed effects controlled in the regressions under different specifications, including month of the year effects, firm fixed effects, and sometimes event fixed effects.

The results on price response with respect to stamp duty changes are shown in Table 4. We start with regressing A-share daily return on H-share daily return, which gives a significant coefficient of 0.57 , suggesting that $\mathrm{H}$-share stocks are a good control for Ashare stocks. Next, we gradually incorporate various sets of fixed effects into the model. In column 3, the simple difference-in-differences regression on the full sample gives a negative and significant estimate of the interaction term between $\mathrm{H}$-share returns and the higher tax dummy, suggesting a short-term return reduction of about 20 basis points $(=0.2274 * 0.0089)$. This is consistent with the average 20 basis points change in the stamp duty in our sample events.

In order to mitigate any potential bias due to outliers, we conduct a subsample analysis by eliminating potential outlier stocks. In column 4, observations with A-share price over $\mathrm{H}$-share price exceeding the $90^{\text {th }}$ percentile of the sample are dropped in the regression. Overall, consistent results are found both in the full sample and subsample, suggesting a significantly negative impact of higher transaction taxes on stock prices.

\subsection{Average Effect on Price Volatility}

Firm level price volatility

In this sub-section, we examine the effect of stamp duty changes on price volatility. For event $m$, the treatment group is the set of A-share stocks in our sample, while the 
control group consists of their corresponding H-share stocks. Because we can match stocks in the treatment and control groups one by one, we can work with firm level data rather than portfolio level data (which is necessary in Jones and Seguin (1997)). We test various model specifications with price volatility of 240 trading days before and after each stamp duty change. We first regress the difference in price volatility between A and $\mathrm{H}$ shares by the following specification:

$$
\Delta \sigma_{m, i, t}=\gamma_{0}+\gamma_{1} H_{i g h e r} t_{\text {tax_dummy }}, i, t+C_{t}+F+\varepsilon_{m, i, t}
$$

The dependent variable is $\Delta \sigma_{m, i, t}$ which captures the difference between A-share and H-share price volatility for event $m$, firm $i$ and day $t$. We use two forms of $\Delta \sigma_{m, i, t}$ : $\left(\sigma_{m, i, t}^{A}-\sigma_{m, i, t}^{H}\right)$ and $\left(\sigma_{m, i, t}^{A} / \sigma_{m, i, t}^{H}\right)$. The first form is the direct difference in volatility between $\mathrm{A}$ and $\mathrm{H}$ shares, whereas the second one is the ratio. The ratio specification does not require the $\mathrm{A}$ and $\mathrm{H}$ volatility to be on the same scale (though they are reasonably close according to Table 2 panel B).

For each event, we use the daily closing prices during the year before and the year after to construct our sample. This length of the event window follows the choice of Jones and Seguin (1997) in order to maintain comparability. We have also tried a window of six months before and six months after each event, and obtained similar qualitative results.

We have considered several different measures of stock price volatility. First, we follow Jones and Seguin (1997) and use a raw (or unfitted) price volatility, which is measured as $\sqrt{\frac{\pi}{2}}\left|R_{m, i, t}\right|$ for event $m$ stock $i$ at day $t$ during a window of 240 trading days before and after an event. By multiplying the absolute change in log price with the scaling coefficient, $\sqrt{\pi / 2}$, we obtain an unbiased estimator of the standard deviation at the daily frequency (assuming log price follows a normal distribution). Second, we use a fitted daily price volatility, defined as the fitted value from a 12-lag auto-regression, i.e. $\sigma_{\mathrm{it}}=\sum_{n=1}^{12} \sigma_{i, t-n}+\varepsilon_{t}$, where $\sigma_{i t}$ is the unsigned daily stock return scaled by $\sqrt{\pi / 2}$. Third, we use a daily price volatility estimated from a two-year time series, calculated as the standard deviation of a firm's daily return in the 240 trading days before and after each stamp duty change. 
Since there are multiple events with opposite adjustment directions (increase/decrease), we define an indicator variable, Higher Tax dummy, which takes a value of one in the regime with a higher stamp duty to simplify the exposition. In the window of 240 trading days before and after an event, the higher tax dummy equals to 1 if day $t$ is in the higher stamp duty period and zero otherwise.

$F$ refers to a set of fixed effect, whereas $C_{t}$ refers to a set of additional controls, including 12-month base interest rates in these two markets respectively. Interest rates are a proxy for discount rates that may affect how cash flows are converted to present values.

Robust standard errors adjusted for heteroskedasticity are clustered at the firm level in our regressions. Note we are not able to cluster standard errors at the event level because the small number of events (7) would have led to bias in standard error estimation according to Petersen (2009). (None of the studies in the literature on this topic cluster standard errors at the event level.) Instead, we include both event and firm fixed effects but cluster standard errors at the firm level. We will also report results event by event in a later part of the paper.

\section{Discussion of the identification strategy}

For the identification to be valid, variations in the stamp duty need to be uncorrelated with the error term. Yet, changes in the stamp duty are presumably not purely random. For our purpose, we need them to be exogenous with respect to the relative volatility between the A and $\mathrm{H}$ share markets. We investigate this issue in two ways.

We use an opportunity of a meeting with a senior official in the China Securities Regulatory Commission, who also happened to be a senior officer of the Shanghai Stock Exchange during 2008-2012, and a senior officer of the Shenzhen Stock Exchange before 2008, to develop an understanding of the determination of stamp duty changes.

Authors: "How are the decisions on adjusting the stamp duty made? Do you ever look at the relative volatility between the $A$ and $H$ share markets and use it as a guide to decide on the level of the stamp duty?"

The official: “The stamp duty is jointly decided by the Ministry of Finance and the CSRC (China Securities Regulatory Commission). We never look at 
relative stock market volatility. We (at the CSRC and the stock exchanges) always advocate a low stamp duty in order to minimize transaction costs. The Ministry of Finance often wants a higher stamp duty, which is a revenue source for them."

Authors: "When would your argument win over the Ministry of Finance?"

The official: "Sometimes when the broad market index is low, the Ministry of Finance would consent to lowering the stamp duty. But it doesn't always work."

Our takeaway from the conversation is that changes in the stamp duty might be endogenous to the level of A-share index but is unlikely to be endogenous to the relative volatility between the A-share and $\mathrm{H}$-share markets because the latter is not something decision makers pay attention to.

We check this out more formally. In the first column of Table 5 panel A, changes in the stamp duty are regressed on three lags of log A-share index. We indeed see that the recent past levels of A-share market index have predictive power for changes in the stamp duty. Perhaps because the policy makers often act with a lag, we see that the coefficients on the second and the third lags of the index are negative (indicating that a lower market index is more likely to predict an increase in the stamp duty, and vice versa). Interestingly, the coefficient on the one-month lag of the market index is positive. It is also noteworthy that the sum of the three coefficients is approximately zero.

In the second column of Table 5 panel A, changes in the stamp duty are regressed on three lags of the relative volatility in the A and $\mathrm{H}$ share markets (averaged equally over all cross-listed stocks). The coefficients on each of the regressors are statistically zero based on individual $t$ tests. An F-test for the null that they are jointly zero, reported at the bottom of the column, also fails to be rejected. This supports the assumption that the decisions on changing the stamp duty do not consider the relative volatility in the two markets.

In the third column, changes in the stamp duties are again regressed on three lags of the relative volatility (averaged over all cross-listed stocks), where the relative volatility for a given stock is now measured by the ratio of the A-share volatility to the H-share

\footnotetext{
${ }^{7}$ A majority of the stamp duty revenue goes to the Ministry of Finance, with a small portion going to the two local governments (Shanghai and Shenzhen) that host the two exchanges. The CSRC and the stock exchanges keep a portion of stock account registration fees, but do not derive revenue from the stamp duty.
} 
volatility. Again, we see no evidence that changes in the stamp duties take into account the relative volatility between the two markets.

In the last two columns of Table 5 panel A, we incorporate both lags of monthly broad market index and lags of relative volatility. These two regressions confirm the previous finding: while the decisions on changing the stamp duty may take into account the recent past of broad market index, they do not appear to consider the relative volatility between the Chinese and the Hong Kong stock markets.

Because there are seven actual changes in the stamp duty, the monthly changes in the stamp duty mostly take on a value of zero. In panel B of Table 5, we look at a substantially reduced sample consisting of the seven months in which the stamp duty changes actually take place plus the six months prior to each of the changes. We find the same qualitative results. In particular, the coefficients on the three lags of relative volatility are both individually and jointly zero (by three t tests and one F test). This is true regardless of the way relative volatility is measured, and regardless of conditioning on lags of broad market index or not. We therefore conclude that changes in the stamp duty do not take into account relative volatility in the two markets.

We will later report a placebo test that will further justify our identification strategy.

\section{$\underline{\text { Regression results }}$}

Panel A of Table 6 reports regression results following equation (2). In column 1, we regress the difference in raw daily price volatility between $\mathrm{A}$ and $\mathrm{H}$ shares on the higher tax dummy, and obtain a negative and significant coefficient of -0.0055 . If we hold $\mathrm{H}$ share price volatility constant, this suggests a $17 \%(=0.0055 / 0.0318)$ reduction in the Ashare price volatility, on average, after moving from a low-tax regime to a high-tax regime. To ensure that the results are not driven by outlier stocks, we also perform a regression in a subsample where we exclude those stock observations whose A share price premium over $\mathrm{H}$ share exceeds the $90^{\text {th }}$ percentiles. The same qualitative results are found in the subsample but the point estimate is somewhat smaller.

In columns 3 and 4 , we substitute the dependent variable with the ratio of fitted daily price volatility of A-share over $\mathrm{H}$-share. Consistently negative and significant coefficients are obtained for both the full sample and the subsample. In terms of 
economic significance, an increase in the stamp duty in our sample is associated with a reduction in price volatility by $15 \%(=0.1375 /(0.000310 / 0.000336))$. Given that the magnitudes of stamp duty adjustments in China are large by international comparisons, this means that a relatively large adjustment in the stamp duty yields a relatively small reduction in price volatility.

Instead of using separately daily price volatility as do Jones and Seguin (1997), we can estimate two daily price volatility for each firm and each event, with one in the pre-event period (over 240 trading days) and the other in the post-event period (also over 240 trading days). Such estimates of daily price volatility should be more precise, although the sample size of the daily price volatility would be substantially smaller. The regression results with this new measure of volatility are reported in columns 5 (for the full sample) and 6 (for the subsample that excludes stocks with an A/H share price gap exceeding the $90^{\text {th }}$ percentile), respectively. Reassuringly, the results turn out be qualitatively the same as before, with the point estimates being somewhat larger than their counterparts in columns 1 and 2.

\section{Alternative specifications}

Following Jones and Seguin (1997), we can consider another way to link the volatility in the treatment and control groups:

$$
\sigma_{m, i, t}^{T}=\gamma_{0}+\gamma_{1} \sigma_{m, i, t}^{C}+\gamma_{2} \sigma_{m, i, t}^{C} \text { Higher_tax_dummy } y_{m, i, t}+C_{t}+F+\varepsilon_{m, i, t},
$$

$\sigma_{m, i, t}^{T}$ and $\sigma_{m, i, t}^{C}$ are the price volatilities of the stock $i$ in event $m$ for treatment and control groups respectively. In this specification, the A share volatility is only assumed to be a linear function of its $\mathrm{H}$ share counterpart, but they don't have always have to have the same scale. The key coefficient for our purpose is, $\gamma_{2}$, on the interaction between the higher tax dummy and the volatility on $\mathrm{H}$ shares. Under the null of no effect from a stamp duty change, $\gamma_{2}$ would be zero. Under the alternative that a higher transaction cost leads to a lower price volatility, $\gamma_{2}$ would be negative.

With this specification, we work with either raw volatility or fitted volatility (from a 12 lag auto-regression). Since time trend in volatility could bias our inference, as a third way to measure volatility, we also take out potential event-specific time trends in the volatility. In panel B of Table 6, we report the regression results with this new 
specification. For each of the three ways of measuring volatility, we run regressions on both the full sample and the subsample that takes out potential outliers in terms of $\mathrm{A} / \mathrm{H}$ share price gaps.

A total of six regressions are reported in panel B of Table 6. In all cases, the coefficients on the interaction between the higher tax dummy and H-share volatility are negative and statistically significant. In the first four columns, an increase in the stamp duty, on average, is associated with a reduction in the price volatility by $3.6 \%$. In the last two columns, the estimates are a bit smaller; an increase in the stamp duty, on average, is associated with a $2 \%$ reduction in the volatility.

\section{$\underline{\text { Placebo test }}$}

To further ensure that our results do not reflect spurious correlations, we conduct a placebo test. We will do it in two steps. First, we will pick a set of fake event days - days on which there are no changes in the stamp duty. Second, we perform regressions similar to column 1 of Table 5 panel A, and see if we would falsely conclude the volatility goes down on the fake event days when there are in fact no increases in the stamp duty.

To pick fake event dates, we make use of the fitted values of regression 1 in Table 5 panel A during 2002-2004; these three years are the longest continuous period in the sample in which there were no changes in the stamp duty. There are a total of six dates on which the absolute values of predicted stamp duty changes exceed 0.20 . We use them as fake event months for a stamp duty increase if the predicted values are positive, and fake event months for a stamp duty decrease if the predicted values are negative. To go from the fake event months to fake event dates, we try three possibilities by defining the fake event dates at the beginning, the middle, or the end of the fake event months, respectively. We pool the six fake events and run three regressions, respectively, by choosing the beginning, middle and end of a fake event month as the corresponding fake dates. We redo the basic difference in differences regressions on these fake events, and report the results in Table 7.

It turns out that the coefficients on the fake higher tax dummy are always statistically indifferent from zero. This is reassuring as we do not obtain a negative coefficient when 
we are not supposed to. This helps to bolster our confidence that our key results are unlikely to be driven by spurious correlations.

\section{$\underline{\text { Extensions }}$}

Several additional regressions are conducted in various subsamples and the results are shown in Table 8. First, we divide up our sample into two subgroups based on the direction of the stamp duty changes. This enables us to capture any asymmetric effect of stamp duty changes. We report the results with the subsample of stamp duty reductions in the first column, and those with stamp duty increases in the second column. In both cases, stamp duty levels and price volatility are negatively related. The effect is somewhat stronger for stamp duty increases than for decreases.

Recognizing that firms in the financial service sector and the utility sector may be systematically different from other manufacturing firms, we also look at a subsample that excludes financial and utility firms. The result is reported in column 3 of Table 8. This does not change the basic pattern that a higher transaction cost is associated with lower price volatility; the magnitude is statistically significant but economically modest.

The validity of an event study approach depends on the maintained assumption that the event in question - a change in the stamp duty in our case - is the only major event during the event window. To gain additional confidence, we manually check for disclosure by each sample firm in the CSMAR database for any significant event around each event date. Several companies underwent a reform where previously non-traded shares were converted to tradable shares during 2005-2008. Some of the conversions took place on dates close to our event dates. In column 4 of Table 8, we re-estimate the model for the subsample of firms without any key events recorded in CASMAR/Factiva/Bloomberg over the event windows. Reassuringly, we find qualitatively similar results as the full sample.

Taken together, our findings suggest that price volatility of A-shares relative to $\mathrm{H}$ shares is lower in the high stamp tax regime and the results are robust in various subsamples. We interpret our findings as evidence to support the advocates' view on the Tobin tax and argue that in the Chinese context, on average, stamp duty does have a positive effect on curbing speculation and reducing excessive volatility. At the same time, 
we find that the economic effect of a change in stamp duties is relatively modest. Given that the changes in the size of the stamp duty in China are already on the high side when compared with other countries' practices, we conclude that an increase in the transaction cost can only modestly reduce the price volatility.

Events such as adjustments in the required reserve capital rate and commission fee, which could potentially affect the price volatility, are also checked and qualitatively similar results are found.

\section{Portfolio level price volatility}

Most studies in the existing literature form portfolios to examine the effects of stamp duty. This is mostly out of necessity as there is a lack of stock-by-stock correspondence between the treatment and control groups. Nevertheless, for comparison purposes, we follow Jones and Seguin (1997) to re-estimate the model with portfolio level data in this section. Equally weighted portfolios of full sample and subsample are estimated following equation (2).

Table 9 shows the regression results. We examine the portfolio price volatility response to stamp duty changes with two model specifications as in Table 6 panel A. First, in columns 1 and 2 of Table 9, we regress the difference in raw price volatility between $\mathrm{A}$ and $\mathrm{H}$ share on the higher tax dummy and find that both the full sample and the subsample estimations give us similar results as the firm level analyses. In terms of magnitude, the effect is strengthened with the portfolio level data. In columns 3 and 4 , we substitute the dependent variable with the ratio of fitted price volatility of A over $\mathrm{H}$ shares and obtain similar results.

Initial level and change size of stamp duties

We further examine the role of initial level and change size of stamp duty adjustments with the following specification.

$$
\begin{aligned}
& \Delta \sigma_{m, i, t}=\gamma_{0}+\gamma_{1} \text { Higher_tax_dummy }_{m, i, t} \\
& +\gamma_{2} \text { Higher_tax_dummy }_{m, i, t} \text { Change_in_A_share_stamp_dutym } \\
& +\gamma_{3} H_{i g h e r} \text { tax_dummy } y_{m, i}, A_{-} \text {share_initial_stamp_duty_level }{ }_{m}+C_{t}+F \\
& +\varepsilon_{m, i, \mathrm{t}}
\end{aligned}
$$


Change_in_A_share_stamp_duty $y_{m}$ refers to the absolute magnitude of A-share stamp duty change in event $\mathrm{m}$, while $A_{-}$share_initial_stamp_duty_level ${ }_{m}$ refers to the initial level of stamp duty prior to any change. Interaction terms between these two variables with the higher tax dummy are also incorporated in the regression to capture their marginal effects on price volatility response.

Ex ante, the effect could go either way. On one hand, a higher initial level of stamp duty prior to adjustment could cause a larger reduction in price volatility when transiting from a low tax regime to a high tax regime. Intuitively, if an investor is taxed at $2 \%$ and another investor is taxed at 4\%o, supposing a $2 \%$ o increase in stamp duty for both investors, one could argue that the second investor with a higher initial level of stamp duty could response more in reducing her investment activities. On the other hand, one could also argue that the relation between initial level of stamp duty and price volatility response is positive, because the effect of stamp duty has been exhausted as the level of stamp duty rises, resulting in a diminishing effect on price volatility changes. We will let the data speak to the issue.

In column 1 of Table 10, we show the results on the magnitude of change in stamp duty, while in column 2, we incorporate terms reflecting initial level of stamp duty prior to changes to the model. Column 3 shows the results of the full sample by incorporating both terms. We find that the adverse effect of stamp duty on price volatility change is fully loaded on the interaction term of initial level of stamp duties. In addition, the negative coefficient for the interaction term suggests that a higher initial level of stamp duty and larger change magnitude are associated with a larger impact on price volatility reduction when moving from a low tax regime to a high tax regime. Similar result for the subsample is shown in column 4.

\subsection{Trading Volume}

We also investigate the impact of stamp duty changes on trading volume. Unlike price volatility, empirical evidence appears to agree that increases in stamp duty reduce trading volume. In our paper, share turnover is adopted as a proxy for trading volume, and is measured as daily trading volume scaled by market capitalization. Firm level data are 
examined in a diff-in-diff regression model as following,

$$
\Delta \text { Turnover }_{m, i, t}=\gamma_{0}+\gamma_{1} \text { Higher_tax_dummy }_{m, i, t}+C_{t}+F+\varepsilon_{m, i, t}
$$

$\Delta$ Turnover $_{m, i, t}$ is the difference in daily share turnover between $\mathrm{A}$ and $\mathrm{H}$ shares for firm $i$ day $t$ in event $m$.

Our results in Table 11 are consistent with the literature which finds a negative relation between stamp duty and trading volume. In column 1 of Table 11, our results show that when switching to a higher tax regime, the turnover drops significantly by about 65\% (=0.0037/0.0057) (holding the turnover for H shares constant). Subsequently, in Table 12, we replicate firm level turnover estimations with portfolio level data. Equally weighted portfolios are constructed as in Table 9. Overall, the portfolio level results are qualitatively similar to firm level ones, but with a quantitatively stronger effect.

\section{Market Development and Evolving Effects of Transaction Costs}

We have argued that the effect of a higher transaction cost on price volatility depends on whether the transaction cost drives out more informed fundamental-based traders or more non-fundamental-based noise traders. The negative effect we have found so far could reflect the fact that the young Chinese stock market has been dominated by nonfundamental-based noise traders. We now aim to extract more insight by exploring a possible heterogeneous volatility response both across time periods and across stocks.

As shown in Figure 2a, there were no institutional shares in the Chinese market in the early part of the sample period and they remain significantly lower than developed markets until recently. For example, in Jones and Seguin (1997), institutional ownership in the U.S. stock market around the time of commission deregulation in 1975 is about 22\%, while for China, the number was lower until 2008. If a greater share of institutional trading implies a proportionately smaller role of speculative noise trading, it would be interesting to examine whether the effect of a higher transaction cost on price volatility is reversed in the later part of the sample period. 


\section{$\underline{4.1 \text { Evolution of Institutional Investors in China }}$}

Guided by Figure 2b, we divide the entire history of the Chinese equity market into three periods of approximately equal length: (1) The infant stage (1990-1997): after the Shanghai and Shenzhen stock exchanges were established in 1990, there were virtually no institutional investors, and the market was almost entirely dominated by retail investors; (2) The toddler stage (1998-2005): institutional investors have emerged though still not significant in trading. Investors became relatively less naive after having experienced several ups and downs in the stock market in the preceding years. (3) The growth stage (after 2006): Institutional investors start to grow at a high speed and play a more important role in the Chinese stock market, while some of the retail investors have also become more sophisticated and more exposed to the knowledge of finance and economics. At the same time, the number of stocks has increased dramatically. Figure 3 provides snapshots of the number of institutional investors and institutional ownership at the firm level in the fourth quarter of 2000 and 2008 respectively. While the exact dividing lines among the three periods are somewhat arbitrary, they roughly divide the history of the Chinese equity market (from late 1990 to now) into three stages of equal length, and are meant to capture the evolution of the relative importance of institutional traders in the market.

We implement the same regression specification as in column 1 of panel A of Table 6 for each time period, and report the results in Table 13. We focus our discussions on the coefficients for the higher tax dummy. Interestingly, we see a negative coefficient for the first two historical periods (1990-1997, and 1998-2005) but a positive coefficient in the more recent period (after 2006). This intriguing pattern of signs is consistent with the notion that, in earlier periods when the market is dominated by retail traders, a higher transaction cost reduces price volatility, whereas in the most recent period when institutional investors have started to play a more important role in the market. It is also interesting to note that, when we allow the effects to be different in different time periods, the volatility suppressing effect of a higher transaction cost has also become bigger in the earlier periods. The coefficients (-0.0073 and -0.0121 , respectively) are bigger than the corresponding coefficient in Table 6. 
This result has the potential to explain the different findings of ours and opponents' of Tobin tax in the literature, such as Jones and Seguin (1997). As pointed out earlier, the institutional share in the Chinese financial market in the growth era reaches a level similar to that of the U.S. market around the time of the commission deregulation in 1975 discussed by Jones and Seguin (1997). Therefore, our findings highlight a potentially important role of investor structure in driving the conflicting evidence in the literature.

In addition to looking at three sub-periods, we perform separate event studies for each of the seven changes in the stamp duty. Table 14 provides event level evidence from univariate and multivariate analyses. First, in panel A of Table 14, we provide the summary statistics of univariate analyses. For each event, changes in price volatility, share turnover, and return are calculated as value in high tax regime minus the value in low tax regime for $\mathrm{A}$ and $\mathrm{H}$ share respectively. T-tests are performed to test the difference between $\mathrm{A}$ and $\mathrm{H}$ shares in terms of the responses of these variables with respect to a change in the stamp duty. For the first five effects (during 1997-2007), higher transaction costs are associated with lower volatility. However, for the last two events (both of which took place in 2008), the opposite correlation is observed.

In panel B of Table 14, we examine the changes in the ratio of A share volatility to $\mathrm{H}$ share volatility, event by event. The qualitative patterns are exactly the same. For the first five events, higher transaction costs are associated with lower volatility; but for the last two events, the correlation is reversed.

The double differencing results at the individual event level are summarized by Figures 5a and 5b, respectively. Across the seven events, on balance, higher transaction costs and lower volatility go together. This can be seen from the fact that most of the data points are in either the Northwest or the Southeast quadrants. In addition, on average, larger increases in the stamp duty are associated with larger decreases in the price volatility. However, this average pattern masks some interesting heterogeneity. In particular, the observations for the last two events are different from the other five.

\subsection{Institutional Share and Price Volatility}

While the results in the previous subsection are suggestive, we cannot read too much into a data pattern from three time periods. Next, we use two direct measures of 
institutional trading in the estimations, constructed with institutional ownership level and number of institutional investors ${ }^{8}$. First, we collect from WIND information on institutional ownership at the firm level on a quarterly basis. The first available data starts from the $2^{\text {nd }}$ quarter of 1998 . For firms without such information, we assign zero institutional ownership at the reporting time. (We also omit firm-quarters with missing information as a robustness check.)

We first conduct the following OLS regressions and report the results in Table 15.

$\Delta \sigma_{m, i, t}=\gamma_{0}+\gamma_{1}$ Higher_tax_dummy $y_{m, i, t}+\gamma_{2} I O_{m, i, t}+\gamma_{3}$ Higher_tax_dummy $y_{m, i, t} I O_{m, i, t}+$ $C_{t}+F+\varepsilon_{m, i, t}$

$I O_{m, i, t}$ refers to the measures of institutional trading. Our first measure is institutional turnover, which is the cumulative absolute change in ownership of each institutional investor in the latest quarter prior to each stamp duty change in our sample. Our second measure of the relative importance of institutional investors at the stock-event level is the $\log (1+$ number of institutional investors in logarithm) following Cornett et al. (2007).

The results are interesting. While the coefficients on the higher tax dummy are always negative and statistically significant across the regressions, the coefficients on the interaction between institutional ownership and the higher tax dummy are always positive and significant. This means that, for stock-periods with low institutional trading, higher transaction taxes are associated with lower price volatility. However, for stock-periods with a sufficiently high level of institutional trading, the opposite association appears higher transaction costs are now associated with higher, not lower, volatility.

Note that we do not assume that every single institutional investor is fundamental investor, and every retail investor is a noise investor. Rather, on average, institutional investors are more likely to be aware of fundamentals and their implication for stock prices than retail investors.

\footnotetext{
${ }^{8}$ Information on institutional ownership for sample A-shares one quarter prior to the stamp duty changes is obtained from the WIND database.
} 


\section{$\underline{4.3 \text { Instrumental variable regressions }}$}

In order to mitigate a potential endogeniety issue in variables reflecting institutional trading, we conduct 2SLS estimations by introducing two sets of instrument variables (IV). The first set of IVs includes the Amihud illiquidity ratio for A-share stock and the natural logarithm of total asset, while the second set of IVs includes the Amihud illiquidity ratio and a dummy variable which equals to one if a stock is a member of the CSI 300 index, and zero otherwise. Firm size and liquidity are well discussed in the literature as correlated with institutional trading or institutional ownership. In addition, after the CSI 300 was established in April 2005, a growing number of funds have benchmarked to it. We argue that a stock that becomes a member of the CSI 300 would naturally attract more institutional trading.

The 2SLS regressions are pursued in the following way. In the first stage, we regress our measures of institutional trading on the IVs following equation (7)

$$
I O_{m, i, t}=\gamma_{0}+\gamma_{1} I V_{1}+\gamma_{2} I V_{2}+F+\varepsilon_{m, i, t}
$$

$I O_{m, i, t}$ refers to the measures of institutional trading as in Table 15, while $I V_{1}$ and $I V_{2}$ refers to the IVs of each IV set used. Results of the first stage regression are reported in panel A of Table 16. The predicted values of $I O_{m, i, t}$ are obtained from the first stage regression, and incorporated into the second stage regressions.

In the second stage regressions, we follow equation (8) to substitute institutional trading measures with predicted value obtained from first stage estimations with instruments.

$$
\begin{aligned}
\Delta \sigma_{m, i, t}=\gamma_{0}+ & \gamma_{1} \text { Higher_tax_dummy }_{m, i, t}+\gamma_{2} \widehat{I O}_{m, i, t}+\gamma_{3} \text { Higher_tax_dummy }_{m, i, t} \widehat{I O}_{m, i, t} \\
& +C_{t}+F+\varepsilon_{m, i, t .}
\end{aligned}
$$

Panel B of Table 16 shows the results of 2SLS regressions. Consistent with the OLS regressions, $\gamma_{1}$ is consistently negative and statistically significant across four regressions. For the interaction terms, regressions show positive and statistically significant coefficients. These results confirm the basic pattern: while higher transaction costs lead to lower volatility for stocks with low institutional investor trading, the reverse is true for stocks with high institutional trading. Based on the point estimates in column 1, the 
switching point occurs when the absolute change in the institutional ownership reaches 14\%. The switching point can be seen visually in Figure 6a (which also plots the switching point implied by the OLS estimates for comparison). If we use the point estimates in column 2, the switching point occurs when the number of institutional investors at the stock level reaches 14. This can be seen in Figure 6b. Of course, the switching point estimates should be interpreted with caution as institutional investors are not homogeneous in terms of their size, awareness of fundamentals, and ability.

We also conduct tests to check the validity of the instruments, and summarize the test results at the bottom of panel B of Table 16. First, we perform a Hausman (1978) test of the endogeneity of the regressors. Test statistics suggest rejection of the null; that is, the regressors are exogenous, which confirms the necessity of using IVs. Second, Hansen's over-identification tests are conducted; we cannot reject the null that the IVs and the error term in the main regression are not correlated. Lastly, Stock and Yogo (2001) tests of weak IV are performed; we can easily reject the null, suggesting that the IVs used in our estimation are not weak.

In panel $\mathrm{C}$ of Table 16, we conduct regressions in the subsample that excludes potential outliers (as defined in earlier sections). The results are consistent with panel B of Table $16 .^{9}$

\section{Conclusion}

While the effect of a Tobin tax on price volatility is an economically important topic, the existing empirical results in the literature are mixed. This paper makes two useful contributions. In terms of methodology, our use of stocks that are simultaneously listed in two segmented markets allows us to have a control group that has identical corporate fundamental as the treatment group, and thus a much cleaner control group than any in the existing empirical studies. In terms of the economic message, we allow the effect of a Tobin tax on price volatility to depend on the maturity of the market; this perspective is also unique relative to all existing empirical studies on the topic.

\footnotetext{
${ }^{9}$ We note that Scheinkman and Xiong (2003) also suggest a link between transaction costs and price volatility under a combination of no short sell constraint and differential degrees of over-confidence across traders. Their model does not generate the empirical pattern that we document here - a reversal of the effects of higher transaction costs on price volatility as the importance of institutional investors grows.
} 
We find evidence that for immature markets, higher transaction costs tend to reduce price volatility. This is intuitive - if the Tobin tax argument has any hope of curbing excessive volatility, one should find it in an immature market where non-fundamental based trading is prevalent. However, we also find evidence that higher transaction costs tend to increase, rather than decrease, volatility in a more mature market (defined by the relative role of institutional investors). This is also intuitive. In such markets, many investors are fundamental based. Higher transaction costs discourage both fundamentalbased and noise traders. By impeding timely incorporation of fundamental information into prices, a Tobin tax could backfire. 


\section{Reference}

Aliber, Robert Z., Chowdhry, Bhagwan and Yan, Shu, 2002, "Some Evidence that a Tobin Tax on Foreign Exchange Transactions may Increase Volatility”, European Finance Review 7: 481-510.

Amihud, Yakov, 2002, "Illiquid and Stock Returns: Cross-Section and Time-Series Effects”, Journal of Financial Markets, 5: 31-56.

Aregger, N., Brown, M. and Enzo, R., 2012, “Can a Transaction Tax or Capital Gains Tax Smooth House Prices?”, working paper

Atkins, Allen B. and Dyl, Edward A., 1997, "Stock Price Volatility, Transaction Costs and Securities Transactions Taxes”, Managerial and Decision Economics, 18(7-8), 709-718.

Baltgi, Badi H., Li, Dong and Li, Qi, 2006, “Transaction Tax and Stock Market Behavior: Evidence from an Emerging Market”, Empirical Economics, 31(2), 393-408.

Chou, Robin K., and Wang, George H. K., 2006, “Transaction Tax and Market Quality of the Taiwan Stock Index Futures”, Journal of Futures markets, 26, 1195-1216.

Chow, Gregory C., 1960, "Tests of Equality between Sets of Coefficients in Two Linear Regressions", Econometrica, 28(3), 591-605.

Cornett, Marcia M., Marcus, Alan, Saunders, Anthony and Tehranian, Hassan, 2007, “The impact of institutional ownership on corporate operating performance”, Journal of Banking and Finance, 31, 1771-1794.

De Long, Bradford, Andrei Shleifer, Lawrence H. Summers, and R. J. Waldman, 1990, “Noise Trader Risk in Financial Markets”, Journal of Political Economy, 98(4), 703-38.

Edwards, F. R., 1993, “Taxing Transactions in the Future Markets: Objectives and Effects.”, Journal of Financial Services, 7, 75-93.

Fernald, John, and John H. Rogers, 2002, “Puzzles in the Chinese Stock Market,” The Review of Economics and Statistics, 84(3): 416-432.

Fu, Yuming, Qian, Wenlan, and Yeung, Bernard, 2012, "Financial Transaction Tax: the Double-edged Sword Effects on Price Stability”, Unpublished working paper, National University of Singapore. 
Gromb, Denis, and Dimitri Vayanos, 2002, Equilibrium and welfare in markets with financially constrained arbitrageurs, Journal of Financial Economics 66, 361-407.

Gromb, Denis, and Dimitri Vayanos, 2010, "Limits of Arbitrage," Annual Review of Financial Economics, 2(1): 251-275.

Gompers, Paul A., and Andrew Metrick, 2001, "Institutional Investors and Equity Prices”, The Quarterly Journal of Economics, 116(1), 229-259.

Green, Christopher J., Maggioni, Paolo and Murinde, Victor, 2000, “ Regulatory Lessons for Emerging Stock markets from A Century of Evidence on Transactions Costs and Share Price Volatility in the London Stock Exchange”, Journal of Banking \& Finance, 24(4), 577-601.

Grundfest, Joseph A., 1990, "The Damning Facts of a New Stocks Tax", Wall Street Journal, July $23^{\text {rd }}$

Grundfest, Joseph A., and Shoven, John B., 1991, “Adverse Implications of a Securities Transaction Excise Tax”, Journal of Accounting, Auditing, and Finance, 6(4): 409-442.

Habermeier, Karl and Kirilenko, Andrei A., 2001, "Securities Transaction Taxes and Financial Markets”, IMF working paper

Hanke, Michael, Huber J., Kirchler, M. and Sutter, M., 2010, "The Economic Consequences of A Tobin Tax - An Experimental Analysis”, Journal of Economic Behavior \& Organization, 74(1-2), 58-71.

Hansen, Lars Peter, 1982, "Large Sample Properties of Generalized Method of Moments Estimators”, Econometric, 50, 1029-1054.

Hau, Harald, 2006, “The Role of Transaction Costs for Financial Volatility: Evidence from the Paris Bourse”, Journal of the European Economic Association, 4(4), 862-890.

Hausman, Jerry A., 1978, "Specification Tests in Econometrics", Econometrica, 46(6), $1251-1271$.

Heaton, John, and Lo, Andrew W., 1993, "The Impact of a Securities Transactions Tax on Financial Markets and Institutions.” Mimeo, Catalyst Institute, Chicago, 1993. 
Hu, Shing-yang, 1998, "The Effects of the Stock Transaction Tax on the Stock Market Experiences from Asian Markets”, Pacific-Basin Finance Journal, 6(3-4), 347364.

Jones, Charles M., and Seguin, Paul J., 1997, "Transaction Costs and Price Volatility: Evidence from Commission Deregulation”, The American Economic Review, 87(4), 728-737.

Kupiec, Paul H., 1996, "Noise Traders, Excessive Volatility, and a Securities Transactions Tax”, Journal of Financial Services Research, 10, 115-129.

Lanne, Markku, and Vesala, Timo, 2010, "The Effect of A Transaction Tax on Exchange Rate Volatility”, International Journal of Finance \& Economics, 15(2), 123-133.

Liu, Shinhua and Zhu, Zhen, 2009, "Transaction Costs and Price Volatility: New Evidence from the Tokyo Stock Exchange”, Journal of Financial Services Research, 36(1): 65-83.

Petersen, Mitchell A., 2009, "Estimating Standard Errors in Finance Panel Data Sets: Comparing Approaches”, The Review of Financial Studies, 22(1), 435-480

Phylakti, Kate S. and Aristidou, Antonis., 2007, "Security Transaction Taxes and Financial Volatility: Athens Stock Exchange”, Applied Financial Economics, 17(18), 1455-1467.

Roll, Richard, 1989, "Price Volatility, International Market Links, and Their Implications for Regulatory Policies”, Journal of Financial Services Research, 3, 211-246.

Scheinkman, Jose, and Xiong, Wei, 2003, "Overconfidence and Speculative Bubbles," Journal of Political Economy, 111(6): 1183-1219.

Schwert, William G. and Seguin, Paul J., 1993, "Securities Transaction Taxes: An Overview of Costs, Benefits, and Unresolved Questions”, Financial Analyst Journal, Sept/Oct, 27-35.

Sheffrin, Steven M. and Turner, Tracy M., 2001, "Taxation and House-Price Uncertainty: Some Empirical Estimates”, International Tax and Public Finance, 8, 621-636.

Song, Frank M., and Zhang, Junxi, 2005, "Securities Transaction Tax and Market Volatility”, The Economic Journal, 115, 1103-1120.

Shleifer, Andrei, 2000, Inefficient Markets: An Introduction to Behavioral Finance, Oxford University Press. 
Shleifer, Andrei, and Robert W. Vishny, 1997, “The Limits of Arbitrage,” The Journal of Finance, 52: 35-55.

Stiglitz, Joseph E., 1989, "Using Tax Policy to Curb Speculative Short-term Trading”, Journal of Financial Services Research, 3(2-3), 101-115.

Stock, James H. and Yogo, M., 2001, "Testing for Weak Instruments in Linear IV Regression.”, NBER Technical Working Paper No. 284.

Summers, Lawrence H. and Summers, Victoria P., 1989, "When Financial Markets Work Too Well: A Cautious Case for a Securities Transaction Tax”, Journal of Financial Services Research, 3(2-3), 261-286.

Tobin, James, 1978, “A Proposal for International Monetary Reform”, Eastern Economic Journal, 4, 153-159.

Tobin, James, 1984, “On the Efficiency of the Financial System”, Lloyd Bank Review, 153, 1-15.

Umlauf, Steven R., 1993, "Transaction Taxes and the Behavior of the Swedish Stock Market”, Journal of Financial Economics, 33(2), 227-240.

Westerholm, Joakim, 2003, “The Impact of Transaction Costs on Turnover, Asset Prices and Volatility: The Cases of Sweden's and Finland's Security Transaction Tax Reductions”, The Finnish Journal of Business Economics, 2(3), 213-241. 
Table 1 Historical adjustment of stamp duties on stock trading in China and Hong Kong Table 1 lists all the historical adjustments of stock trading stamp duty in China (A-share) and Hong Kong after 1993 when the first cross-listed firm appeared.

\begin{tabular}{ll}
\hline \multicolumn{1}{c}{ Date } & \multicolumn{1}{c}{ Activities } \\
\hline \multicolumn{2}{c}{ Panel A: Historical adjustments of stamp duty on stock trading in China } \\
12-May-97 & Trading stamp tax increased from 6\%o to 10\%o (buyers and sellers each pay half) \\
12-Jun-98 & Trading stamp tax reduced from 10\%o to 8\%o \\
16-Nov-01 & Trading stamp tax reduced from 8\%o to 4\%o \\
23-Jan-05 & Trading stamp tax reduced from 4\%o to 2\%o \\
30-May-07 & Trading stamp tax increased from 2\%o to 6\%o \\
24-Apr-08 & Trading stamp tax reduced from 6\%o to 2\%o \\
19-Sep-08 & Trading stamp tax for buyer abolished, while stamp tax for seller remains at 1\%o \\
\hline Panel B: Historical adjustments of stamp duty on stock trading in Hong Kong \\
1-Apr-98
\end{tabular}


Table 2 Summary Statistics

Table 2 reports the summary statistics of our sample firms. The sample contains 223 unique firm-event observations from 1997 to 2008. In panel A, we first provide the mean and median of firm characteristics for our sample stocks and the entire A-share market in 1996 and 2008 respectively. The information is acquired from CSMAR and WIND for the annual or the $4^{\text {th }}$ quarter filing. In panel B, stock characteristics of sample firms' A and $\mathrm{H}$ shares are reported respectively. For each variable, the average over 2 year (480 trading days) around each stamp duty change is reported. Institutional ownership is calculated as a fraction of total market capitalization of tradable shares in the same reporting period. Institutional turnover is measured as absolute change in institutional holding one quarter prior to stamp duty changes, while number of institutional investors is obtained directly from WIND database. All the value variables are reported in RMB, and for H-shares, we convert the HKD to RMB based on the historical daily exchange rate. Appendix has the details on variable definition.

\begin{tabular}{lcccc} 
Panel A: Firm Characteristics & \multicolumn{2}{c}{1996} & \multicolumn{2}{c}{2008} \\
& $\begin{array}{c}\text { Cross-listed } \\
\text { sample }\end{array}$ & A-share market & $\begin{array}{c}\text { Cross-listed } \\
\text { Sample }\end{array}$ & A-share market \\
\hline Currency: RMB & Mean/Median & Mean/Median & Mean/Median & Mean/Median \\
\hline No. observations & 13 & 602 & 51 & 1,712 \\
Total asset (mil) & $5,989 / 3,244$ & $1,244 / 659$ & $703,067 / 56,459$ & $9,427 / 1,959$ \\
Sales (mil) & $3,041 / 1,516$ & $632 / 301$ & $108,805 / 36,836$ & $4,586 / 1,191$ \\
EBIT/Sales & $7.3 \% / 5.4 \%$ & $14.1 \% / 10.7 \%$ & $11.5 \% / 5.5 \%$ & $-1.6 \% / 4.3 \%$ \\
Net income margin & $5.9 \% / 3.9 \%$ & $12.6 \% / 10.1 \%$ & $9.2 \% / 4.3 \%$ & $2.9 \% / 4.7 \%$ \\
Sales growth & $-2.9 \% / 1.2 \%$ & $8.1 \% / 2.3 \%$ & $15.7 \% / 17.5 \%$ & $17.8 \% / 10.0 \%$ \\
Cash/Total asset & $16.7 \% / 19.1 \%$ & $10.0 \% / 8.0 \%$ & $11.5 \% / 8.1 \%$ & $16.0 \% / 12.8 \%$ \\
Debt/Total asset & $6.0 \% / 3.9 \%$ & $5.1 \% / 2.2 \%$ & $11.9 \% / 8.6 \%$ & $5.9 \% / 1.0 \%$ \\
Institutional ownership & $0.0 \% / 0.0 \%$ & $0.0 \% / 0.0 \%$ & $35.1 \% / 29.3 \%$ & $23.2 \% / 17.3 \%$ \\
Institutional turnover & $0.0 \% / 0.0 \%$ & $0.0 \% / 0.0 \%$ & $15.6 \% / 9.2 \%$ & $7.7 \% / 2.7 \%$ \\
Number of institutional investors & $0 / 0$ & $0 / 0$ & $62 / 31$ & $16 / 6$ \\
\hline
\end{tabular}

\section{Panel B: Stock Characteristics}

Currency: RMB

A-share

H-share

Market Capitalization (mil)

126,836

37,326

Stock price

13.7

6.4

Average value of daily transaction volume (mil)

282

Average daily return

$0.07 \%$

$0.01 \%$

Average daily price volatility (unfitted)

0.0318

0.0355

Average daily price volatility (fitted)

0.0310

0.0336

Annual price volatility

0.0328

0.0373

Average daily share turnover

0.0057

0.0119

Amihud illiquidity ratio

0.0015

0.0356 


\section{Table 3 Variable Correlation Matrix}

Table 3 provides the correlation matrix of the key variables in our analyses. Volatility refers to the fitted daily price volatility which he is measured as $\sqrt{\frac{\pi}{2}}\left|R_{m, i, t}\right|$ for event m stock $\mathrm{i}$ at day $\mathrm{t}$ conditional on 12 previous daily price volatility followed Jones and Seguin (1997). Ret refers to daily stock return and Turnover refers to the daily share turnover, measured as $\frac{\text { volume }_{m, i, t}}{{\text { Total share outstanding } g_{i, i}}_{\text {f }}}$ for event $\mathrm{m}$ stock i at day t. Inst. own refers to the institutional ownership which is obtained in the latest quarter prior to each stamp duty change. Inst turnover refers to the cumulative absolute quarterly change in ownership of each institutional investor of a sample A-share in the latest quarter prior to stamp duty changes relative to one quarter before. No. of ins.t investor is the number of institutional investors for each sample firm in the latest quarter prior to stamp duty changes. Initial stamp duty is the initial level of stamp duty in A-share market prior to each stamp duty change, while change stamp duty refers to the change in stamp duty for each stamp duty change. Please note that in subsequent regressions, we use the absolute size of stamp duty change instead of the change stamp duty which also reflects the direction of the change. Lastly, interest rate in China and HK are monthly rates reflecting the 12-month base rates. Details on the variable definition can be found in an appendix.

\begin{tabular}{|c|c|c|c|c|c|c|c|c|c|c|c|c|c|}
\hline & $\begin{array}{l}\text { Volatility } \\
\text { (A) }\end{array}$ & $\begin{array}{c}\text { Volatility } \\
(\mathrm{H})\end{array}$ & $\begin{array}{l}\text { Ret } \\
\text { (A) }\end{array}$ & $\begin{array}{l}\text { Ret } \\
(\mathrm{H})\end{array}$ & $\begin{array}{c}\text { Turnover } \\
\text { (A) }\end{array}$ & $\begin{array}{c}\text { Turnover } \\
(\mathrm{H})\end{array}$ & $\begin{array}{l}\text { Inst. } \\
\text { own }\end{array}$ & $\begin{array}{c}\text { Inst. } \\
\text { turnover }\end{array}$ & $\begin{array}{c}\text { No. of } \\
\text { inst. } \\
\text { investors }\end{array}$ & $\begin{array}{c}\text { Initial } \\
\text { stamp } \\
\text { duty }\end{array}$ & $\begin{array}{c}\text { Change } \\
\text { stamp } \\
\text { duty }\end{array}$ & $\begin{array}{l}\text { Interest } \\
\text { rate } \\
\text { (China) }\end{array}$ & $\begin{array}{c}\text { Interest } \\
\text { rate } \\
\text { (HK) }\end{array}$ \\
\hline Volatility (A) & 1.00 & & & & & & & & & & & & \\
\hline Volatility (H) & 0.27 & 1.00 & & & & & & & & & & & \\
\hline Ret (A) & 0.01 & 0.01 & 1.00 & & & & & & & & & & \\
\hline Ret $(\mathrm{H})$ & 0.00 & 0.02 & 0.35 & 1.00 & & & & & & & & & \\
\hline Turnover (A) & 0.30 & 0.09 & 0.17 & 0.07 & 1.00 & & & & & & & & \\
\hline Turnover $(\mathrm{H})$ & 0.11 & 0.33 & 0.07 & 0.17 & 0.17 & 1.00 & & & & & & & \\
\hline Inst. own & 0.10 & -0.03 & 0.00 & 0.01 & -0.02 & 0.09 & 1.00 & & & & & & \\
\hline Inst. turnover & 0.08 & -0.02 & 0.00 & 0.01 & 0.01 & 0.10 & 0.73 & 1.00 & & & & & \\
\hline No. of inst. investors & 0.03 & -0.01 & 0.00 & 0.00 & -0.03 & 0.09 & 0.63 & 0.61 & 1.00 & & & & \\
\hline Initial stamp duty & -0.18 & 0.13 & -0.01 & -0.01 & -0.19 & -0.02 & -0.38 & -0.40 & -0.37 & 1.00 & & & \\
\hline Change stamp duty & 0.09 & -0.06 & 0.02 & 0.01 & 0.10 & 0.01 & -0.10 & 0.01 & -0.03 & -0.53 & 1.00 & & \\
\hline Interest rate (China) & 0.05 & 0.15 & -0.02 & -0.03 & -0.10 & 0.01 & -0.29 & -0.25 & -0.19 & 0.37 & 0.31 & 1.00 & \\
\hline Interest rate (HK) & -0.04 & -0.08 & 0.01 & 0 & -0.07 & 0.01 & -0.29 & -0.23 & -0.29 & 0.24 & 0.36 & 0.40 & 1.00 \\
\hline
\end{tabular}




\section{Table 4 Price Response to Stamp Duty Changes}

This table reports the price response to announcement of stamp duty adjustment. Dependent variable is daily return of our sample A-shares. We focus on the short-term price response in 2 trading days before and after each stamp duty change. Daily returns of $\mathrm{H}$-share within the same window are used as independent variable. Higher tax dummy equals to 1 if the day $\mathrm{t}$ is in the higher stamp duty period and zero otherwise. In columns 1-3, results on full-sample estimations are reported, while results on subsample estimation excluding observations of "crazy stocks" which have price (A-share)/price (H-share) above 90th percentiles of the full sample are reported in column 4. Firm, year, month of the year, and event fixed effects are controlled under different specifications. Robust standard errors adjusted for heteroskedasticity and firm level clustering are reported in the parentheses. ${ }^{* * *}, * *$, and * indicate statistically significant at $1 \%, 5 \%$ and $10 \%$ level respectively.

\begin{tabular}{|c|c|c|c|c|}
\hline \multirow[b]{3}{*}{ VARIABLES } & \multicolumn{4}{|c|}{ Return(A-share) } \\
\hline & \multicolumn{3}{|c|}{ Full sample } & \multirow{2}{*}{$\begin{array}{c}\text { Subsample } \\
\text { (4) }\end{array}$} \\
\hline & (1) & (2) & (3) & \\
\hline \multirow[t]{2}{*}{ Return (H-share) } & $0.5719 * * *$ & $0.6233^{* * *}$ & $0.6082 * * *$ & $0.5945 * * *$ \\
\hline & $(0.0311)$ & $(0.0360)$ & $(0.0463)$ & $(0.0499)$ \\
\hline \multirow[t]{2}{*}{ Return (H-share)*Higher tax dummy } & & $-0.1640 * * *$ & $-0.2274^{* * *}$ & $-0.2483^{* * *}$ \\
\hline & & $(0.0551)$ & $(0.0743)$ & $(0.0770)$ \\
\hline Observations & 892 & 892 & 892 & 736 \\
\hline Firm fixed effects & No & Yes & Yes & Yes \\
\hline Year fixed effects & No & No & Yes & Yes \\
\hline Month of the year fixed effects & No & No & Yes & Yes \\
\hline Event fixed effects & No & No & Yes & Yes \\
\hline Standard error cluster & Firm & Firm & Firm & Firm \\
\hline $\mathrm{R}$-square & 0.2746 & 0.3121 & 0.3586 & 0.3900 \\
\hline
\end{tabular}


Table 5 Stamp Duty Changes

Tables below present the results of regressions of monthly changes in the stamp duty in the Chinese market on log A-share index of the previous three months, and on the relative volatility of the cross-listed stocks in the $\mathrm{A}$ and $\mathrm{H}$ markets of the previous three months. In panel A, the series of regressions are run for the entire period from 1996 to 2009, while in panel B, the same regressions are run in a subsample consisting of the seven months in which the stamp duty changes actually take place plus the six months prior to the change. F-tests that the coefficients for lagged variables of the logarithm of A-share index value are jointly zero, and that those for relatively volatility of cross-listed stocks jointly zero, are reported respectively. ***, **, and * indicate statistically significant at $1 \%, 5 \%$ and $10 \%$ level respectively.

Panel A: full sample 1996-2009, monthly

\begin{tabular}{|c|c|c|c|c|c|}
\hline \multirow[b]{2}{*}{ VARIABLES } & \multicolumn{5}{|c|}{ Change of stamp duty } \\
\hline & (1) & (2) & (3) & (4) & (5) \\
\hline \multirow[t]{2}{*}{$\operatorname{Lag}(1)$ of $\log (A$ index $)$} & $2.10 * * *$ & & & $2.06^{* * *}$ & $2.04 * * *$ \\
\hline & $(0.58)$ & & & $(0.59)$ & $(0.59)$ \\
\hline \multirow[t]{2}{*}{$\operatorname{Lag}(2)$ of $\log (A$ index $)$} & $-1.66^{* *}$ & & & $-1.72^{* *}$ & $-1.65 *$ \\
\hline & $(0.83)$ & & & $(0.84)$ & $(0.84)$ \\
\hline \multirow[t]{2}{*}{$\operatorname{Lag}(3)$ of $\log (\mathrm{A}$ index $)$} & -0.47 & & & -0.37 & -0.43 \\
\hline & $(0.57)$ & & & $(0.58)$ & $(0.58)$ \\
\hline \multirow[t]{2}{*}{$\operatorname{Lag}(1)$ of $[\mathrm{V}(\mathrm{A})-\mathrm{V}(\mathrm{H})]$} & & 0.01 & & -0.05 & \\
\hline & & $(0.12)$ & & $(0.12)$ & \\
\hline \multirow[t]{2}{*}{$\operatorname{Lag}(2)$ of $[\mathrm{V}(\mathrm{A})-\mathrm{V}(\mathrm{H})]$} & & 0.20 & & 0.18 & \\
\hline & & $(0.13)$ & & $(0.13)$ & \\
\hline \multirow[t]{2}{*}{$\operatorname{Lag}(3)$ of $[\mathrm{V}(\mathrm{A})-\mathrm{V}(\mathrm{H})]$} & & -0.06 & & -0.05 & \\
\hline & & $(0.12)$ & & $(0.12)$ & \\
\hline \multirow[t]{2}{*}{$\operatorname{Lag}(1)$ of $[\mathrm{V}(\mathrm{A}) / \mathrm{V}(\mathrm{H})]$} & & & -0.57 & & -1.90 \\
\hline & & & (3.34) & & (3.28) \\
\hline \multirow{2}{*}{$\operatorname{Lag}(2)$ of $[\mathrm{V}(\mathrm{A}) / \mathrm{V}(\mathrm{H})]$} & & & 5.71 & & 5.09 \\
\hline & & & (3.58) & & $(3.47)$ \\
\hline \multirow[t]{2}{*}{$\operatorname{Lag}(3)$ of $[V(A) / V(H)]$} & & & -0.66 & & -0.50 \\
\hline & & & (3.34) & & $(3.24)$ \\
\hline Observations & 165 & 165 & 165 & 165 & 165 \\
\hline R-square & 0.09 & 0.02 & 0.02 & 0.10 & 0.10 \\
\hline F-test (market index lags jointly $=0$ ) & $4.97^{* * *}$ & & & $4.48^{* * *}$ & $4.57 * * *$ \\
\hline F-test (volatility lags jointly $=0$ ) & & 1.09 & 1.10 & 0.69 & 0.80 \\
\hline
\end{tabular}


Panel B: subsample includes event months and 6 months before actual event month

\begin{tabular}{|c|c|c|c|c|c|}
\hline \multirow[b]{2}{*}{ VARIABLES } & \multicolumn{5}{|c|}{ Change of stamp duty } \\
\hline & $(1)$ & $(2)$ & (3) & (4) & (5) \\
\hline \multirow[t]{2}{*}{$\operatorname{Lag}(1)$ of $\log (A$ index $)$} & $4.94 * * *$ & & & $4.71 * * *$ & $4.71 * * *$ \\
\hline & $(1.57)$ & & & $(1.62)$ & $(1.63)$ \\
\hline \multirow[t]{2}{*}{$\operatorname{Lag}(2)$ of $\log (A$ index $)$} & $-4.36 *$ & & & $-4.23 *$ & -4.14 \\
\hline & $(2.41)$ & & & $(2.49)$ & $(2.52)$ \\
\hline \multirow[t]{2}{*}{$\operatorname{Lag}(3)$ of $\log (A$ index $)$} & -0.52 & & & -0.41 & -0.51 \\
\hline & $(1.58)$ & & & $(1.66)$ & $(1.66)$ \\
\hline \multirow[t]{2}{*}{$\operatorname{Lag}(1)$ of $[\mathrm{V}(\mathrm{A})-\mathrm{V}(\mathrm{H})]$} & & 0.07 & & 0.03 & \\
\hline & & $(0.32)$ & & $(0.30)$ & \\
\hline \multirow[t]{2}{*}{$\operatorname{Lag}(2)$ of $[\mathrm{V}(\mathrm{A})-\mathrm{V}(\mathrm{H})]$} & & 0.39 & & 0.29 & \\
\hline & & $(0.34)$ & & $(0.32)$ & \\
\hline \multirow[t]{2}{*}{$\operatorname{Lag}(3)$ of $[\mathrm{V}(\mathrm{A})-\mathrm{V}(\mathrm{H})]$} & & -0.11 & & -0.13 & \\
\hline & & $(0.31)$ & & $(0.29)$ & \\
\hline \multirow[t]{2}{*}{$\operatorname{Lag}(1)$ of $[\mathrm{V}(\mathrm{A}) / \mathrm{V}(\mathrm{H})]$} & & & 1.33 & & 1.64 \\
\hline & & & $(8.08)$ & & (7.69) \\
\hline \multirow[t]{2}{*}{$\operatorname{Lag}(2)$ of $[\mathrm{V}(\mathrm{A}) / \mathrm{V}(\mathrm{H})]$} & & & 9.04 & & 5.83 \\
\hline & & & (8.03) & & $(7.67)$ \\
\hline \multirow[t]{2}{*}{$\operatorname{Lag}(3)$ of $[\mathrm{V}(\mathrm{A}) / \mathrm{V}(\mathrm{H})]$} & & & -1.11 & & -1.95 \\
\hline & & & $(7.62)$ & & $(7.24)$ \\
\hline Observations & 51 & 51 & 51 & 51 & 51 \\
\hline R-square & 0.19 & 0.05 & 0.04 & 0.21 & 0.21 \\
\hline F-test (market index lags jointly $=0$ ) & $3.68^{* *}$ & & & $3.05 * *$ & $3.09 * *$ \\
\hline F-test (volatility lags jointly $=0$ ) & & 0.76 & 0.63 & 0.38 & 0.29 \\
\hline
\end{tabular}




\section{Table 6 Stamp Duties and Stock Price Volatility}

The table reports results on the effects of stamp duty changes on price volatility within 240 trading days before and after each adjustment date. In panel A, we follow $\Delta \sigma_{m, i, t}=\gamma_{0}+\gamma_{1}$ Higher_tax_dummy $_{m, i, t}+C_{t}+F+\varepsilon_{m, i, t}$, where $\Delta \sigma_{m, i, t}$ measures the difference between A-share and H-share daily price volatility for event $\mathrm{m}$, firm i and day t. Higher tax dummy equals to 1 if day $\mathrm{t}$ is in the higher stamp duty period and zero otherwise, while $C$ refers to the controls and $F$ refers to the various types of fixed effects. In columns 1 and 2, we first use the difference of raw daily price volatility between $\mathrm{A}$ and $\mathrm{H}$ share as the dependent variable.

The raw price volatility is measured as $\sqrt{\frac{\pi}{2}}\left|R_{m, i, t}\right|$ for event $\mathrm{m}$ stock i at day t according to Jones and Seguin (1997). In columns 3 and 4 , we substitute the dependent variable by the ratio of fitted price volatility of $\mathrm{A}$ and $\mathrm{H}$ shares. The fitted daily price volatility is the fitted value from a 12-lag auto regression of the raw volatility. In columns 5 and 6, the price volatility is estimated from absolute value of daily returns for each event-firm observations before and after stamp duty changes. In addition, we control the 12-month base interest rate for China and HK respectively with monthly frequency. Firm, year, month of the year, and event fixed effects are controlled under different specifications. Robust standard errors adjusted for heteroskedasticity and firm level clustering are reported in the parentheses. ${ }^{* * *},{ }^{* *}$, and $*$ indicate statistically significant at $1 \%, 5 \%$ and $10 \%$ level respectively.

\begin{tabular}{|c|c|c|c|c|c|c|}
\hline \multirow{2}{*}{$\begin{array}{l}\text { Panel A } \\
\text { VARIABLES }\end{array}$} & \multicolumn{2}{|c|}{$\begin{array}{l}\mathrm{V}(\mathrm{A})-\mathrm{V}(\mathrm{H}) \\
\text { (Unfitted price volatility) }\end{array}$} & \multicolumn{2}{|c|}{$\begin{array}{l}\qquad \mathrm{V}(\mathrm{A}) / \mathrm{V}(\mathrm{H}) \\
\text { (Fitted price volatility) }\end{array}$} & \multicolumn{2}{|c|}{$\begin{array}{c}\mathrm{V}(\mathrm{A})-\mathrm{V}(\mathrm{H}) \\
\text { (estimated price volatility from one year of } \\
\text { data) }\end{array}$} \\
\hline & $\begin{array}{c}\text { Full sample } \\
(1)\end{array}$ & $\begin{array}{c}\text { Subsample } \\
(2) \\
\end{array}$ & $\begin{array}{c}\text { Full sample } \\
\text { (3) }\end{array}$ & $\begin{array}{c}\text { Subsample } \\
(4) \\
\end{array}$ & $\begin{array}{c}\text { Full sample } \\
\text { (5) }\end{array}$ & $\begin{array}{c}\text { Subsample } \\
(6)\end{array}$ \\
\hline Higher tax dummy & $\begin{array}{c}-\mathbf{0 . 0 0 5 5} 5^{* * *} \\
(0.0010)\end{array}$ & $\begin{array}{c}-\mathbf{0 . 0 0 4 8} * * * \\
(0.0009)\end{array}$ & $\begin{array}{c}-\mathbf{0 . 1 3 7 5} * * * \\
(0.0206)\end{array}$ & $\begin{array}{c}-\mathbf{0 . 1 1 2 4} \\
(0.0170 *)\end{array}$ & $\begin{array}{c}-\mathbf{0 . 0 0 7 1} \\
(0.0009)\end{array}$ & $\begin{array}{c}-\mathbf{0 . 0 0 6 2} * * * \\
(0.0009)\end{array}$ \\
\hline Interest rate (China) & $\begin{array}{c}0.0387 \\
(0.0366)\end{array}$ & $\begin{array}{c}0.0400 \\
(0.0347)\end{array}$ & $\begin{array}{c}4.9203^{* * *} \\
(0.6771)\end{array}$ & $\begin{array}{c}4.3780 * * * \\
(0.5695)\end{array}$ & $\begin{array}{c}0.2660 * * * \\
(0.0360)\end{array}$ & $\begin{array}{c}0.2959 * * * \\
(0.0342)\end{array}$ \\
\hline Interest rate (HK) & $\begin{array}{c}0.2572 * * * \\
(0.0202)\end{array}$ & $\begin{array}{c}0.2202 * * * \\
(0.0222)\end{array}$ & $\begin{array}{c}5.3763^{* * *} \\
(0.3400)\end{array}$ & $\begin{array}{c}5.0018^{* * *} \\
(0.3380)\end{array}$ & $\begin{array}{c}0.2738 * * * \\
(0.0217)\end{array}$ & $\begin{array}{c}0.2112 * * * \\
(0.0222)\end{array}$ \\
\hline Observations & 100,898 & 79,244 & 100,343 & 78,827 & 446 & 446 \\
\hline Firm fixed effects & Yes & Yes & Yes & Yes & No & No \\
\hline Month of the year fixed effects & Yes & Yes & Yes & Yes & No & No \\
\hline Event fixed effects & Yes & Yes & Yes & Yes & Yes & Yes \\
\hline Standard error cluster & Firm & Firm & Firm & Firm & Firm & Firm \\
\hline R-square & 0.0555 & 0.0729 & 0.1717 & 0.1725 & 0.5287 & 0.5568 \\
\hline
\end{tabular}


In panel B, we follow $\sigma_{m, i, t}^{T}=\gamma_{0}+\gamma_{1} \sigma_{m, i, t}^{C}+\gamma_{2} \sigma_{m, i, t}^{C}$ Higher_tax_dummy ${ }_{m, i, t}+C_{t}+F+\varepsilon_{m, i, t}$, where $\sigma_{m, i, t}^{T}$ measures the daily price volatility for the treatment group, while $\sigma_{m, i, t}^{C}$ measures the daily price volatility of control H-shares. In columns 1 and 2 of panel B, we first regress the unfitted daily price volatility of Ashare following the above model specification. In columns 3 and 4, we substitute the measure of daily price volatility with the value after detrending. For detrending, we regress unfitted daily price volatility $\sigma_{m, i, t}$ on $t$ for each stamp duty change, and use the residual of the regression as the detrended variables. In columns 5 and 6, we follow Jones and Seguin (1997) and regress the fitted A-share price volatility following $\hat{\sigma}_{m, i, t}^{T}=\gamma_{0}+\gamma_{1} \hat{\sigma}_{m, i, t}^{C}+\gamma_{2} \hat{\sigma}_{m, i, t}^{C}$ Higher_tax_dummy $_{m, i, t}+C_{t}+F+\varepsilon_{m, i, t}$.

Panel B

\section{VARIABLES}

Price volatility (H-share)

Price volatility (H-share)* Higher tax dummy

Interest rate (China)

Interest rate (HK)

\section{Observations}

Firm fixed effects

Year fixed effects

Month of the year fixed effects

Event fixed effects

Standard error cluster
(Unfitted price volatility)

Full sample Subsample
Price volatility (A-share) (Detrended unfitted price volatility) Full sample Subsample

(3)

$0.1747 * * *$
$(0.0091)$

(2)

$0.2449 * * *$

\section{$-\mathbf{0 . 0 3 6 1 * * *}$}

(0.0086)

$0.1579 * * *$

(0.0399)

$-0.0256$

(0.0248)

(0.0104)

$0.1780 * * *$

(0.0090)

$-\mathbf{0 . 0 3 6 3}$ ***

(0.0095)

$0.1847^{* * *}$

(0.0343)

$-0.0031$

(0.0255)

$\begin{array}{cc}100,898 & 79,244 \\ \text { Yes } & \text { Yes } \\ \text { Yes } & \text { Yes } \\ \text { Yes } & \text { Yes } \\ \text { Yes } & \text { Yes } \\ \text { Firm } & \text { Firm } \\ 0.1362 & 0.1794\end{array}$

\section{$-\mathbf{0 . 0 3 6 9}$ ***}

(0.0087)

0.0755*

(0.0381)

$-0.1148 * * *$

(0.0248)

100,898

Yes

Yes

Yes

Yes

Firm
(4)

$0.2475^{* * *}$

(0.0107)

$-\mathbf{0 . 0 3 6 7 * * *}$

(0.0114)

$0.1061 * * *$

(0.0307)

$-0.1198 * * *$

(0.0250)

79,244
Yes
Yes
Yes
Yes
Firm
0.0927

(Fitted price volatility)

Full sample Subsample (6)

$0.1371^{* * *} \quad 0.1376^{* * *}$

(0.0091)

(0.0091)

$\mathbf{- 0 . 0 1 7 6 * *}$

$\mathbf{0 . 0 2 2 7 * * *}$

$(0.0081)$

(0.0084)

$0.1048 * * * \quad 0.1073 * * *$

(0.0285) (0.0282)

$-0.0563 * * * \quad-0.0596 * * *$

(0.0140)

(0.0147)

$\begin{array}{cc}100,343 & 78,827 \\ \text { Yes } & \text { Yes } \\ \text { Yes } & \text { Yes } \\ \text { Yes } & \text { Yes } \\ \text { Yes } & \text { Yes } \\ \text { Firm } & \text { Firm } \\ 0.3666 & 0.3713\end{array}$




\section{Table 7 Placebo Regressions}

Table 7 provides the results of placebo regressions with fake event dates chosen based on estimations in Table 5 column 1 . Specifically, we regress monthly stamp duty changes on 3 lags of log monthly market index value from 1996 to 2009. Next, we pick fake event dates based on the predicted value of the regression (i.e., whose absolute value is above 0.2 as the potential pool for fake event dates). Further, we require the fake events to be within the time period without any actual event. This includes (1999.01 2000.11), (2002.04 -2004.01) and (2005.06-2006.05). We require the starting point to be after 6 months of actual event and the end point to be one year before subsequent actual event date. For each selected fake event month, we choose the beginning, middle, and end of the month to generate 3 sets of fake event dates. For each set of fake dates, we pool the events and run the regression as in column 1 of panel A in Table 6 . To mitigate noises and ensure sufficient observations, 270 days before and after each fake stamp duty change is examined instead of a 240 trading days. ${ }^{* *}, * *$, and * indicate statistically significant at $1 \%, 5 \%$ and $10 \%$ level respectively.

\begin{tabular}{lccc} 
& \multicolumn{3}{c}{$\mathrm{V}(\mathrm{A})-\mathrm{V}(\mathrm{H})$} \\
VARIABLES & Beginning of month & $\begin{array}{c}\text { (Unfitted price volatility) } \\
\text { Middle of month }\end{array}$ & End of month \\
\hline Higher tax dummy & $\mathbf{0 . 0 0 0 2}$ & $\mathbf{- 0 . 0 0 0 2}$ & $\mathbf{- 0 . 0 0 0 1}$ \\
& $(0.0007)$ & $(0.0008)$ & $(0.0007)$ \\
Interest rate (China) & $-0.2407^{* *}$ & $-0.2793^{* * *}$ & $-0.3099^{* * *}$ \\
& $(0.0926)$ & $(0.0981)$ & $(0.1060)$ \\
Interest rate (HK) & $-0.2892^{* * *}$ & $-0.2672^{* * *}$ & $-0.2308^{* * *}$ \\
& $(0.0690)$ & $(0.0790)$ & $(0.0811)$ \\
Observations & & & \\
Firm fixed effects & 43,252 & 43,212 & 43,408 \\
Month of the year fixed effects & Yes & Yes \\
Event fixed effects & Yes & Yes & Yes \\
Standard error cluster & Yes & Yes & Yes \\
R-squared & Firm & Firm & Firm \\
\hline
\end{tabular}




\section{Table 8 Extensions}

In columns 1 and 2, we separate our sample into two groups based on the direction of stamp duty change. Column 1 shows the results on subsample which experience stamp duty reductions, while column 2 shows the results on subsample with increase in stamp duty. In column 3, financial and utility firms are excluded. In column 4, firm observations with significant events, e.g. massive non-tradable shares transfer to tradable shares, over the event window are excluded. Robust standard errors adjusted for heteroskedasticity. ***, **, and $*$ indicate statistically significant at $1 \%, 5 \%$ and $10 \%$ level respectively.

\begin{tabular}{|c|c|c|c|c|}
\hline \multirow[b]{3}{*}{ VARIABLES } & \multicolumn{4}{|c|}{$\mathrm{V}(\mathrm{A})-\mathrm{V}(\mathrm{H})$} \\
\hline & (1) & (2) & (3) & (4) \\
\hline & $\begin{array}{l}\text { Reduce stamp } \\
\text { duty events }\end{array}$ & $\begin{array}{l}\text { Increase stamp } \\
\text { duty events }\end{array}$ & $\begin{array}{c}\text { Excluding } \\
\text { financial \& } \\
\text { utility sectors) }\end{array}$ & $\begin{array}{l}\text { Excluding firms } \\
\text { with significant } \\
\text { event) }\end{array}$ \\
\hline \multirow[t]{2}{*}{ Higher tax dummy } & $-0.0049 * * *$ & $-0.0126 * * *$ & $-0.0073^{* * *}$ & $-0.0086 * * *$ \\
\hline & $(0.0007)$ & $(0.0022)$ & $(0.0011)$ & $(0.0013)$ \\
\hline \multirow[t]{2}{*}{ Interest rate (China) } & $-0.1612^{* * *}$ & $0.2937^{*}$ & $0.0713^{*}$ & $0.0646^{*}$ \\
\hline & $(0.0415)$ & $(0.1592)$ & $(0.0416)$ & $(0.0346)$ \\
\hline \multirow[t]{2}{*}{ Interest rate (HK) } & $0.3204^{* * *}$ & $-0.3755^{* * *}$ & $0.2291^{* * *}$ & $0.2410^{* * *}$ \\
\hline & $(0.0241)$ & $(0.1354)$ & $(0.0280)$ & $(0.0324)$ \\
\hline Observations & 77,414 & 23,484 & 66,079 & 68,405 \\
\hline Firm fixed effects & Yes & Yes & Yes & Yes \\
\hline Month of the year fixed effects & Yes & Yes & Yes & Yes \\
\hline Event fixed effects & Yes & Yes & Yes & Yes \\
\hline Standard error cluster & Firm & Firm & Firm & Firm \\
\hline R-square & 0.0600 & 0.0683 & 0.0544 & 0.0599 \\
\hline
\end{tabular}

\section{Table 9 Portfolio Price Volatility}

Equally weighted portfolios and daily price volatilities in 240 trading days before and after each stamp duty changes are tested. Robust standard errors adjusted for heteroskedasticity and autocorrelation are reported in the parentheses. ${ }^{* *},{ }^{* *}$, and $*$ indicate statistically significant at $1 \%, 5 \%$ and $10 \%$ level respectively.

\begin{tabular}{lcccc} 
& \multicolumn{2}{c}{$\mathrm{V}(\mathrm{A})-\mathrm{V}(\mathrm{H})$} & \multicolumn{2}{c}{$\mathrm{V}(\mathrm{A}) / \mathrm{V}(\mathrm{H})$} \\
& (Unfitted price volatility) & \multicolumn{2}{c}{ (Fitted price volatility) } \\
VARIABLES & Full sample & Subsample & Full sample & Subsample \\
\hline Higher tax dummy & $\mathbf{- 0 . 0 1 2 2 ^ { * * * }}$ & $\mathbf{- 0 . 0 1 1 8 * * *}$ & $\mathbf{- 0 . 1 8 8 5 * * *}$ & $\mathbf{- 0 . 2 3 3 9 * * *}$ \\
& $(0.0016)$ & $(0.0015)$ & $(0.0207)$ & $(0.0211)$ \\
Interest rate (China) & 0.0011 & 0.0012 & $0.0559^{* * *}$ & $0.0511^{* * *}$ \\
& $(0.0011)$ & $(0.0010)$ & $(0.0115)$ & $(0.0096)$ \\
Interest rate (HK) & $0.0023^{* * *}$ & $0.0019^{* * *}$ & $0.0380^{* * *}$ & $0.0500^{* * *}$ \\
& $(0.0005)$ & $(0.0004)$ & $(0.0060)$ & $(0.0062)$ \\
& & & & \\
Observations & 3,356 & 3,284 & 3,356 & 3,200 \\
Month of the year fixed effects & Yes & Yes & Yes & Yes \\
Event fixed effects & Yes & Yes & Yes & Yes \\
R-square & 0.0909 & 0.1087 & 0.2012 & 0.2993 \\
\hline
\end{tabular}


Table 10 Effects of Size of Change and Initial Level of Stamp Duties

Both absolute size of change and initial level of stamp duties are in units of \%o. Robust standard errors adjusted for heteroskedasticity and firm level clustering are reported in the parentheses. ***, **, and * indicate statistically significant at $1 \%, 5 \%$ and $10 \%$ level respectively.

\begin{tabular}{|c|c|c|c|c|}
\hline \multirow[b]{3}{*}{ VARIABLES } & \multicolumn{4}{|c|}{$\mathrm{V}(\mathrm{A})-\mathrm{V}(\mathrm{H})$} \\
\hline & \multicolumn{3}{|c|}{ Full sample } & \multirow{2}{*}{$\begin{array}{c}\text { Subsample } \\
(4) \\
\end{array}$} \\
\hline & (1) & (2) & (3) & \\
\hline \multirow[t]{2}{*}{ Higher tax dummy } & $0.0047 * * *$ & $0.0074 * * *$ & $0.0077^{* * *}$ & $0.0076 * * *$ \\
\hline & $(0.0010)$ & $(0.0009)$ & $(0.0012)$ & $(0.0011)$ \\
\hline \multicolumn{5}{|c|}{ Size of change in A-share stamp duty* } \\
\hline \multirow[t]{2}{*}{ Higher tax dummy } & $-3.2587 * * *$ & & -0.1400 & $-1.0044 * * *$ \\
\hline & $(0.4613)$ & & $(0.3825)$ & $(0.3722)$ \\
\hline \multicolumn{5}{|c|}{ Initial size of A-share stamp duty* } \\
\hline \multirow[t]{2}{*}{ Higher tax dummy } & & $-3.0653 * * *$ & $-3.0309 * * *$ & $-2.2268 * * *$ \\
\hline & & $(0.2626)$ & $(0.2595)$ & $(0.2331)$ \\
\hline \multirow[t]{2}{*}{ Interest rate (China) } & $-0.0680^{*}$ & $0.1769 * * *$ & $0.1708^{* * *}$ & $0.1037 * *$ \\
\hline & $(0.0367)$ & $(0.0535)$ & $(0.0488)$ & $(0.0421)$ \\
\hline \multirow[t]{2}{*}{ Interest rate (HK) } & $0.2409 * * *$ & $0.2830^{* * *}$ & $0.2820^{* * *}$ & $0.2305^{* * *}$ \\
\hline & $(0.0202)$ & $(0.0195)$ & $(0.0210)$ & $(0.0235)$ \\
\hline Observations & 100,898 & 100,898 & 100,898 & 79,244 \\
\hline Firm fixed effects & Yes & Yes & Yes & Yes \\
\hline Month of the year fixed effects & Yes & Yes & Yes & Yes \\
\hline Event fixed effects & Yes & Yes & Yes & Yes \\
\hline Standard error cluster & Firm & Firm & Firm & Firm \\
\hline R-square & 0.0578 & 0.0640 & 0.0640 & 0.0796 \\
\hline
\end{tabular}

\section{Table 11: Effects of Transaction Costs on Share Turnover}

Daily share turnover is calculated as $\frac{\text { volume }_{m, i t}}{\text { Total share outstandingm,i, }_{m}}$ for event m stock i at day $\mathrm{t}$, Subsample estimations exclude potential outliers with price(A-share)/price(H-share) above the 90 th percentiles. ***, **, and * indicate statistically significant at $1 \%, 5 \%$ and $10 \%$ level respectively.

\begin{tabular}{lcccc} 
& \multicolumn{2}{c}{ Turnover(A)-Turnover(H) } & \multicolumn{2}{c}{ Turnover(A)/Turnover(H) } \\
VARIABLES & Full sample & Subsample & Full sample & Subsample \\
\hline Higher tax dummy & $\mathbf{- 0 . 0 0 3 7 ^ { * * * }}$ & $\mathbf{- 0 . 0 0 3 6 * * *}$ & $\mathbf{- 1 . 1 7 3 5 * * *}$ & $\mathbf{- 0 . 9 9 6 3 * * *}$ \\
& $(0.0004)$ & $(0.0005)$ & $(0.3492)$ & $(0.2933)$ \\
Interest rate (China) & $-0.1065^{* * *}$ & $-0.1133^{* * *}$ & -5.3412 & -0.7110 \\
& $(0.0303)$ & $(0.0318)$ & $(16.1307)$ & $(14.3994)$ \\
Interest rate (HK) & $0.0311^{* *}$ & 0.0214 & 8.2809 & 8.3708 \\
& $(0.0142)$ & $(0.0161)$ & $(9.6805)$ & $(7.2391)$ \\
Observations & & & & \\
Firm fixed effects & 100,898 & 79,244 & 95,877 & 79,240 \\
Month of the year fixed effects & Yes & Yes & Yes & Yes \\
Event fixed effects & Yes & Yes & Yes & Yes \\
Standard error cluster & Yes & Yes & Yes & Yes \\
R-square & Firm & Firm & Firm & Firm \\
\hline
\end{tabular}


Table 12 Portfolio Share Turnover

The table reports the results of diff-in-diff regression with portfolio turnover. Equally weighted portfolios are formed and daily share turnovers of the sample in 240 trading days before and after each stamp duty changes are estimated. Subsample excludes stock observations with top $10 \%$ in terms of price (A-share)/ price (H-share). ${ }^{* * *},{ }^{* *}$, and $*$ indicate statistically significant at $1 \%, 5 \%$ and $10 \%$ level respectively.

\begin{tabular}{lcccc} 
& \multicolumn{2}{c}{ Turnover(A)-Turnover(H) } & \multicolumn{2}{c}{ Turnover(A)/Turnover(H) } \\
VARIABLES & Full sample & Subsample & Full sample & Subsample \\
\hline Higher tax dummy & $\mathbf{- 0 . 0 0 5 6 * * *}$ & $\mathbf{- 0 . 0 0 5 6 * * *}$ & $\mathbf{- 0 . 3 8 6 0 * * *}$ & $\mathbf{- 0 . 3 4 7 6 * * *}$ \\
& $(0.0006)$ & $(0.0006)$ & $(0.0473)$ & $(0.0463)$ \\
Interest rate (China) & $-0.0015^{* * *}$ & $-0.0012^{* * *}$ & 0.0135 & $0.0597^{* * *}$ \\
& $(0.0004)$ & $(0.0005)$ & $(0.0231)$ & $(0.0212)$ \\
Interest rate (HK) & $0.0004^{* *}$ & 0.0002 & $0.0392^{* * *}$ & $0.0247^{* * *}$ \\
& $(0.0002)$ & $(0.0002)$ & $(0.0084)$ & $(0.0076)$ \\
Observations & & & & \\
Month of the year fixed effects & 3,356 & 3,284 & 3,235 & 3,284 \\
Event fixed effects & Yes & Yes & Yes & Yes \\
R-square & Yes & Yes & Yes & Yes \\
& 0.1796 & 0.1677 & 0.2015 & 0.1908 \\
\hline
\end{tabular}

\section{Table 13: Effects of Stamp Duties on Price Volatility over Time}

We divide the history of the Chinese stock market into three approximately equally spaced sub-periods: 1990-1997, 1998-2005, and post-2006 period. ***, **, and * indicate statistically significant at $1 \%, 5 \%$ and $10 \%$ level respectively.

\begin{tabular}{|c|c|c|c|}
\hline VARIABLES & $\begin{array}{c}(1) \\
\text { Infant stage } \\
(1990-1997)\end{array}$ & $\begin{array}{l}\text { volatility (A-s) } \\
\text { (2) } \\
\text { Toddler stage } \\
(1998-2005)\end{array}$ & $\begin{array}{c}(3) \\
\text { Growth stage } \\
\text { (after 2006) }\end{array}$ \\
\hline \multirow[t]{2}{*}{ Higher tax dummy } & $-0.0073 * *$ & $-0.0121 * * *$ & $0.0028 * * *$ \\
\hline & $(0.0026)$ & (0.0009) & $(0.0006)$ \\
\hline \multirow[t]{2}{*}{ Interest rate (China) } & $-9.1857^{* * *}$ & $-0.1292 * *$ & -0.1088 \\
\hline & $(1.3247)$ & $(0.0579)$ & $(0.0700)$ \\
\hline \multirow[t]{2}{*}{ Interest rate (HK) } & $-16.2659 * * *$ & $-0.0806 * *$ & $0.2169 * * *$ \\
\hline & (1.9743) & $(0.0370)$ & $(0.0202)$ \\
\hline Observations & 6,888 & 29,142 & 64,868 \\
\hline Firm fixed effects & Yes & Yes & Yes \\
\hline Month of the year fixed effects & Yes & Yes & Yes \\
\hline Event fixed effects & Yes & Yes & Yes \\
\hline Standard error cluster & Firm & Firm & Firm \\
\hline R-square & 0.1868 & 0.0868 & 0.0586 \\
\hline
\end{tabular}


Table 14: Separate Estimates by Event

In panel A, we first report the descriptive statistics of the effects of stamp duty changes on price volatility, share turnover, and price level over 240 trading days before and after stamp duty changes. Because of different directions of stamp duty changes among the 7 events, we report the statistics always as the value in higher tax regime minus the value in lower tax regime. For event $\mathrm{m}$, price volatility is constructed followed Jones and Seguin (1997) as $\sqrt{\pi / 2} \times\left|R_{m, i, t}\right|$, where $R_{m, i, t}$ is the daily return of stock $\mathrm{i}$ and at day $\mathrm{t}$. Share turnover is calculated as $\frac{\text { volume }_{\text {m,it }}}{\text { Total share outstanding } m_{m, t}}$ for stock $\mathrm{i}$ at day t. In panel B, we report the regression estimation of the key variable higher tax dummy for each event. Month of the year and firm fixed effects are controlled for. Standard errors are corrected for heteroskedasticity and reported in the parentheses. ${ }^{* * *}$, **, and * indicate significant at $1 \%, 5 \%$ and $10 \%$ level respectively.

\section{Panel A}

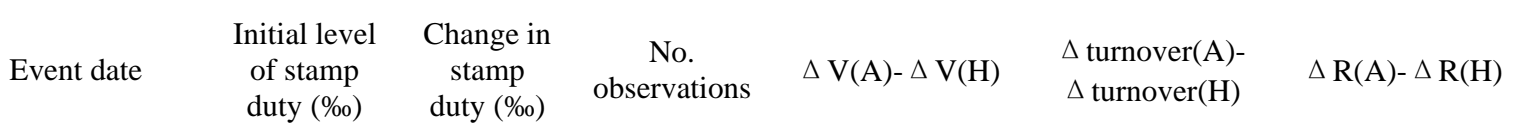

\begin{tabular}{lcccccc}
\hline 12-May-97 & 6 & 4 & 13 & $-0.0442^{* * *}$ & $-0.0160^{* * *}$ & $-0.0049^{*}$ \\
12-Jun-98 & 10 & -2 & 16 & $-0.0135^{* * *}$ & $-0.0122^{* * *}$ & $0.0048^{* * *}$ \\
16-Nov-01 & 8 & -4 & 21 & $-0.0198^{* * *}$ & $-0.0108^{* * *}$ & $-0.0042^{* * *}$ \\
23-Jan-05 & 4 & -2 & 29 & $-0.0103^{* * *}$ & $-0.0044^{* *}$ & $-0.0007^{*}$ \\
30-May-07 & 2 & 4 & 42 & $-0.0144^{* *}$ & $-0.0039^{* * *}$ & $-0.0121^{* * *}$ \\
24-Apr-08 & 6 & -4 & 51 & $0.0105^{* * *}$ & -0.0013 & 0.0003 \\
19-Sep-08 & 1 & -1 & 51 & $0.0150^{* * *}$ & -0.0007 & $0.0012^{*}$ \\
\hline
\end{tabular}

Panel B

Estimation of Coefficient of Higher tax dummy

$\mathrm{V}(\mathrm{A})-\mathrm{V}(\mathrm{H})$

$\mathrm{V}(\mathrm{A}) / \mathrm{V}(\mathrm{H})$

$\mathrm{V}(\mathrm{A})-\mathrm{V}(\mathrm{H})$

\begin{tabular}{lccc} 
Event date & (Unfitted price volatility) & (Fitted price volatility) & (Annual price volatility) \\
\hline 12-May-97 & $-0.0342^{* * *}$ & $-0.6255^{* * *}$ & $-0.0318^{* * *}$ \\
12-Jun-98 & $-0.0102^{* * *}$ & $-0.0852^{* * *}$ & $-0.0065^{* * *}$ \\
16-Nov-01 & $-0.0183^{* * *}$ & $-0.2759^{* * *}$ & $-0.0186^{* * *}$ \\
23-Jan-05 & $-0.0105^{* * *}$ & $-0.3150^{* * *}$ & $-0.0109^{* * *}$ \\
30-May-07 & -0.0008 & $-0.0180^{* * *}$ & $-0.0022^{*}$ \\
24-Apr-08 & $0.0083^{* * *}$ & $0.1467^{* * *}$ & $0.0066^{* * *}$ \\
19-Sep-08 & $0.0122^{* * *}$ & $0.2251^{* * *}$ & $0.0116^{* * *}$ \\
\hline
\end{tabular}




\section{Table 15: Institutional Shares and Price Volatility}

OLS estimates on the role of institutional trading for the stock price volatility response to stamp duty changes. We follow $\Delta \sigma_{m, i, t}=\gamma_{0}+\gamma_{1}$ Higher_tax_dummy $_{m, i, t}+\gamma_{2}$ Higher_tax_dummy $_{m, i, t} I O_{m, i, t}+\gamma_{3} I O_{m, i, t}+C_{t}+F+\varepsilon_{m, i, t}$ to examine the effect of institutional trading on price volatility response to stamp duty changes. Firm, month of the year, and event fixed effects are controlled for, and robust standard errors adjusted for heteroskedasticity and firm level clustering are reported in the parentheses. ${ }^{* * *}, * *$, and * indicate statistically significant at $1 \%, 5 \%$ and $10 \%$ level respectively.

\begin{tabular}{|c|c|c|c|c|c|c|}
\hline \multirow[b]{3}{*}{ VARIABLES } & \multicolumn{6}{|c|}{ Price volatility (A-share) } \\
\hline & \multicolumn{2}{|c|}{$\begin{array}{c}\mathrm{V}(\mathrm{A})-\mathrm{V}(\mathrm{H}) \\
\text { (raw price volatility) }\end{array}$} & \multicolumn{2}{|c|}{$\begin{array}{c}\mathrm{V}(\mathrm{A}) / \mathrm{V}(\mathrm{H}) \\
\text { (Fitted price volatility) }\end{array}$} & \multicolumn{2}{|c|}{$\begin{array}{c}\mathrm{V}(\mathrm{A})-\mathrm{V}(\mathrm{H}) \\
\text { (price volatility estimated from } \\
\text { annual data) }\end{array}$} \\
\hline & $(1)$ & $(2)$ & $(3)$ & $(4)$ & $(5)$ & $(6)$ \\
\hline \multirow[t]{2}{*}{ Higher tax dummy } & $-0.0086 * * *$ & $-0.0156 * * *$ & $-0.1852 * * *$ & $-0.2954 * * *$ & $-0.0099 * * *$ & $-0.0162 * * *$ \\
\hline & $(0.0013)$ & $(0.0014)$ & $(0.0269)$ & $(0.0266)$ & $(0.0013)$ & $(0.0015)$ \\
\hline \multirow[t]{2}{*}{ Institutional turnover } & $-0.0194 * * *$ & & $-0.3342 * * *$ & & $-0.0158 * * *$ & \\
\hline & $(0.0046)$ & & $(0.0973)$ & & $(0.0046)$ & \\
\hline \multirow[t]{2}{*}{ Institutional turnover * Higher tax dummy } & $0.0318 * * *$ & & $0.4819 * * *$ & & $0.0290 * * *$ & \\
\hline & $(0.0078)$ & & $(0.1433)$ & & $(0.0077)$ & \\
\hline \multirow[t]{2}{*}{ Ln(No. institutional investors +1 ) } & & $-0.0036 * * *$ & & $-0.0659 * * *$ & & $-0.0032 * * *$ \\
\hline & & $(0.0005)$ & & $(0.0101)$ & & $(0.0005)$ \\
\hline \multirow[t]{2}{*}{ Ln(No. institutional investors +1 )* Higher tax dummy } & & $0.0049 * * *$ & & $0.0773 * * *$ & & $0.0046 * * *$ \\
\hline & & $(0.0006)$ & & $(0.0098)$ & & $(0.0006)$ \\
\hline \multirow[t]{2}{*}{ Interest rate (China) } & 0.0520 & $0.0921^{* *}$ & $5.1217 * * *$ & $5.7520^{* * *}$ & $0.2937 * * *$ & $0.3611^{* * *}$ \\
\hline & $(0.0380)$ & $(0.0415)$ & $(0.6939)$ & $(0.7399)$ & $(0.0383)$ & $(0.0424)$ \\
\hline \multirow[t]{2}{*}{ Interest rate (HK) } & $0.2466 * * *$ & $0.2106^{* * *}$ & $5.2199 * * *$ & $4.6709 * * *$ & $0.2548 * * *$ & $0.1998 * * *$ \\
\hline & $(0.0222)$ & $(0.0221)$ & $(0.3769)$ & $(0.3901)$ & $(0.0253)$ & $(0.0263)$ \\
\hline Observations & 100,898 & 100,898 & 100,343 & 100,343 & 446 & 446 \\
\hline Firm fixed effects & Yes & Yes & Yes & Yes & No & No \\
\hline Month of the year fixed effects & Yes & Yes & Yes & Yes & No & No \\
\hline Event fixed effects & Yes & Yes & Yes & Yes & Yes & Yes \\
\hline Standard error cluster & Firm & Firm & Firm & Firm & Firm & Firm \\
\hline R-square & 0.0580 & 0.0643 & 0.1766 & 0.1895 & 0.6393 & 0.7232 \\
\hline
\end{tabular}


Table 16: Instrumental Variable Estimates

Two sets of instruments are used: The first set of IVs includes Amihud illiquidity ratio for A-share stock and log total asset; The second set of IVs includes Amihud illiquidity ratio for A-share stock and a dummy variable for stocks that are members of the CSI 300 index. First stage estimation follows $I O_{m, i, t}=\gamma_{0}+$ $\gamma_{1} I V_{1}+\gamma_{2} I V_{2}+F+\varepsilon_{m, i, t}$. In panel A, we report results of the $1^{\text {st }}$ stage regression. In the second stage, we estimate $\quad \Delta \sigma_{m, i, t}=\gamma_{0}+\gamma_{1}$ Higher_tax_dummy $_{m, i, t}+\gamma_{2}$ Higher_tax_dummy $_{m, i, t} \widehat{I O}_{m, i, t}+\gamma_{3} \widehat{I O}_{m, i, t}+C_{t}+F+$ $\varepsilon_{m, i, t}$. In panel B, we provide the results of $2^{\text {nd }}$ stage estimations for full sample first. In columns 1 and 2 , we provide regression estimations when institutional trading variables are estimated with IV set 1 , while in columns 3 and 4, we provide results institutional trading variables estimated with IV set 2 . In addition, for each set of instruments, we perform Hausman (1978) test of the endogeneity of regressors, overidentification test followed Hansen (1982), and weak IV test followed Stock and Yogo (2001). Test statistics are reported in the following table and * denotes rejection of the null hypothesis. In panel $\mathrm{C}$, we repeat our estimations as panel B in subsample excluding "crazy stocks” with price(A-share)/price(H-share) above 90th percentiles of the full sample. Higher tax dummy equals to 1 if the day $t$ is in the higher stamp duty time period and zero otherwise. In addition, we control the 12-month base interest rate for China and HK respectively with monthly frequency. Also, firm, month of the year, and event fixed effects are controlled in different specifications. Robust standard errors adjusted for heteroskedasticity and firm level clustering are reported in the parentheses. ${ }^{* *},{ }^{* *}$, and * indicate statistically significant at $1 \%, 5 \%$ and $10 \%$ level respectively.

\begin{tabular}{lcccc} 
Panel A: $\mathbf{1}^{\text {st }}$ stage & \multicolumn{2}{c}{ Institutional turnover } & \multicolumn{2}{c}{ Ln(no. institutional investors+1) } \\
VARIABLES & $(1)$ & $(2)$ & $(3)$ & $(4)$ \\
\hline Amihud illiquidity ratio (A-share) & $-10.1386^{* * *}$ & $-8.5258^{* * *}$ & $-114.1341^{* * *}$ & $-123.9504^{* * *}$ \\
& $(3.0258)$ & $(2.3287)$ & $(35.1791)$ & $(29.0311)$ \\
Ln(asset) & $0.0099^{* *}$ & & $0.2484^{* * *}$ & \\
& $(0.0041)$ & & $(0.0426)$ & \\
CSI300 member dummy & & $0.0773^{* * *}$ & & $1.2412^{* * *}$ \\
& & $(0.0176)$ & & $(0.1924)$ \\
& & & & \\
Observations & 223 & 223 & 223 & 223 \\
Year fixed effects & Yes & Yes & Yes & Yes \\
Standard error cluster & Firm & Firm & Firm & Firm \\
R-square & 0.2480 & 0.2772 & 0.6915 & 0.6961 \\
\hline
\end{tabular}


Table 16 Panel B: $2^{\text {nd }}$ stage (full sample)

$\mathrm{V}(\mathrm{A})-\mathrm{V}(\mathrm{H})$

\begin{tabular}{|c|c|c|c|c|}
\hline \multirow[b]{2}{*}{ VARIABLES } & \multicolumn{2}{|c|}{ IV set 1} & \multicolumn{2}{|c|}{ IV set 2} \\
\hline & $(1)$ & $(2)$ & (3) & (4) \\
\hline \multirow[t]{2}{*}{ Higher tax dummy } & $-0.0198 * * *$ & $-0.0219 * * *$ & $-0.0194 * * *$ & $-0.0244 * * *$ \\
\hline & $(0.0023)$ & $(0.0025)$ & $(0.0021)$ & $(0.0026)$ \\
\hline \multirow[t]{2}{*}{ Institutional turnover } & $-0.0830 * * *$ & & $-0.0703 * * *$ & \\
\hline & $(0.0221)$ & & $(0.0136)$ & \\
\hline \multirow[t]{2}{*}{ Institutional turnover*Higher tax dummy } & $0.1497 * * *$ & & $0.1408 * * *$ & \\
\hline & $(0.0200)$ & & $(0.0145)$ & \\
\hline \multirow[t]{2}{*}{ Ln(no. institutional investors +1 ) } & & $-0.0044 * *$ & & $-0.0045^{* * *}$ \\
\hline & & $(0.0017)$ & & $(0.0009)$ \\
\hline \multirow{2}{*}{$\begin{array}{l}\text { Ln(no. institutional investors+1) } \\
\text { *Higher tax dummy }\end{array}$} & & $0.0081 * * *$ & & $0.0090 * * *$ \\
\hline & & $(0.0011)$ & & $(0.0009)$ \\
\hline \multirow[t]{2}{*}{ Interest rate (China) } & $0.1035^{* * *}$ & $0.0877 * *$ & $0.1297 * * *$ & $0.1284^{* * *}$ \\
\hline & $(0.0379)$ & $(0.0371)$ & $(0.0389)$ & $(0.0389)$ \\
\hline \multirow[t]{2}{*}{ Interest rate (HK) } & $0.2008 * * *$ & $0.2058^{* * *}$ & $0.2091^{* * *}$ & $0.2102^{* * *}$ \\
\hline & $(0.0236)$ & $(0.0227)$ & $(0.0224)$ & $(0.0224)$ \\
\hline Observations & 100,898 & 100,898 & 100,898 & 100,898 \\
\hline Firm fixed effects & Yes & Yes & Yes & Yes \\
\hline Month of the year fixed effects & Yes & Yes & Yes & Yes \\
\hline Event fixed effects & Yes & Yes & Yes & Yes \\
\hline Standard error cluster & Firm & Firm & Firm & Firm \\
\hline R-square & 0.0603 & 0.0602 & 0.0628 & 0.0628 \\
\hline
\end{tabular}

\section{$\underline{\text { IV Tests }}$}

\begin{tabular}{|c|c|c|c|c|}
\hline & \multicolumn{2}{|c|}{ IV set 1} & \multicolumn{2}{|c|}{ IV set 2} \\
\hline & $\begin{array}{c}\text { Institutional } \\
\text { turnover }\end{array}$ & $\begin{array}{c}\text { Log (no. } \\
\text { Institutional } \\
\text { Investors+1) } \\
\end{array}$ & $\begin{array}{c}\text { Institutional } \\
\text { turnover }\end{array}$ & $\begin{array}{c}\text { Log (no. } \\
\text { Institutional } \\
\text { Investors+1) } \\
\end{array}$ \\
\hline $\begin{array}{l}\text { Hausman (H0: Regressors } \\
\text { are exogenous) }\end{array}$ & F-stat $=152.31 *$ & F-stat $=10.42 *$ & F-stat $=266.13^{*}$ & F-stat $=31.23 *$ \\
\hline $\begin{array}{l}\text { Over-identification (H0: } \\
\text { IVs are not correlated with } \\
\text { the error) }\end{array}$ & J-test $=0.16$ & $\mathrm{~J}$-test $=0.76$ & J-test $=0.02$ & J-test $=0.22$ \\
\hline Stock-Yogo (H0:weak IV) & F-stat $=2955.25^{*}$ & F-stat $=5848.84 *$ & F-stat $=1794.35^{*}$ & F-stat $=7957.33^{*}$ \\
\hline
\end{tabular}


Table 16 Panel C: $2^{\text {nd }}$ stage (subsample)

$\mathrm{V}(\mathrm{A})-\mathrm{V}(\mathrm{H})$

\begin{tabular}{|c|c|c|c|c|}
\hline \multirow[b]{2}{*}{ VARIABLES } & \multicolumn{2}{|c|}{ IV set 1} & \multicolumn{2}{|c|}{ IV set 2} \\
\hline & $(1)$ & $(2)$ & (3) & (4) \\
\hline \multirow[t]{2}{*}{ Higher tax dummy } & $-0.0162 * * *$ & $-0.0182 * * *$ & $-0.0170 * * *$ & $-0.0213^{* * *}$ \\
\hline & $(0.0020)$ & $(0.0021)$ & $(0.0020)$ & $(0.0024)$ \\
\hline \multirow[t]{2}{*}{ Institutional turnover } & -0.0305 & & $-0.0550 * * *$ & \\
\hline & $(0.0223)$ & & $(0.0125)$ & \\
\hline \multirow[t]{2}{*}{ Institutional turnover*Higher tax dummy } & $0.1169 * * *$ & & $0.1208 * * *$ & \\
\hline & $(0.0168)$ & & $(0.0134)$ & \\
\hline \multirow[t]{2}{*}{ Ln(no. institutional investors+1) } & & -0.0003 & & $-0.0036 * * *$ \\
\hline & & $(0.0018)$ & & $(0.0008)$ \\
\hline Ln(\#institutional investors+1) & & $0.0065 * * *$ & & $0.0078 * * *$ \\
\hline *Higher tax dummy & & $(0.0009)$ & & $(0.0008)$ \\
\hline \multirow[t]{2}{*}{ Interest rate (China) } & $0.0879 * *$ & $0.0768 * *$ & $0.1156^{* * *}$ & $0.1149 * * *$ \\
\hline & $(0.0378)$ & $(0.0370)$ & $(0.0337)$ & $(0.0336)$ \\
\hline \multirow[t]{2}{*}{ Interest rate $(\mathrm{HK})$} & $0.1773 * * *$ & $0.1797 * * *$ & $0.1782 * * *$ & $0.1790^{* * *}$ \\
\hline & $(0.0248)$ & $(0.0242)$ & $(0.0239)$ & $(0.0239)$ \\
\hline Observations & 79,244 & 79,244 & 79,244 & 79,244 \\
\hline Firm fixed effects & Yes & Yes & Yes & Yes \\
\hline Month of the year fixed effects & Yes & Yes & Yes & Yes \\
\hline Event fixed effects & Yes & Yes & Yes & Yes \\
\hline Standard error cluster & Firm & Firm & Firm & Firm \\
\hline R-square & 0.0763 & 0.0765 & 0.0789 & 0.0790 \\
\hline
\end{tabular}


Figure 1 Evolution of Stamp Duties in China and Hong Kong

The figure shows the evolution of trading stamp duty (sum over buyers and sellers) in A-share and H-share markets. Y-axis shows the absolute level of stamp duty in \%o.

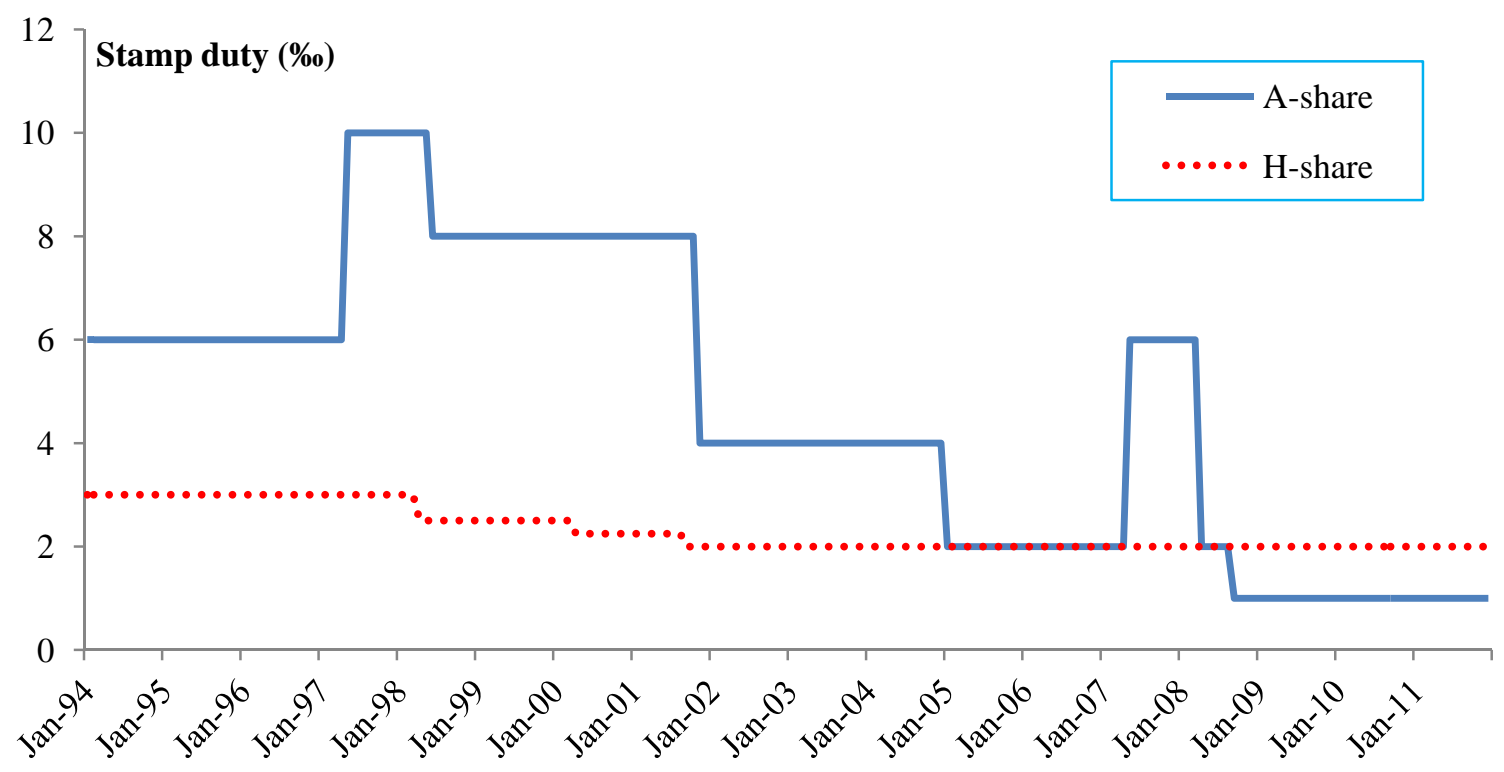




\section{Figure 2 Evolution of Institutional Investors in China}

Information on Chinese institutional holding is from WIND database on semi-annual basis from 1999 to 2012. Figure 2a reports the absolute number of institutional investors in the Chinese market. Figure 2b reports the proportion of institutional holding in the market capitalization for the Chinese A-share market (1998-2012) and the US market (1950-2006), respectively. The broken line indicates the level of institutional investor share in the US market in 1975 (the year of the event studied by Jones and Sequin (1997)).

\section{Fig 2a Size of Institutional Investors Group}

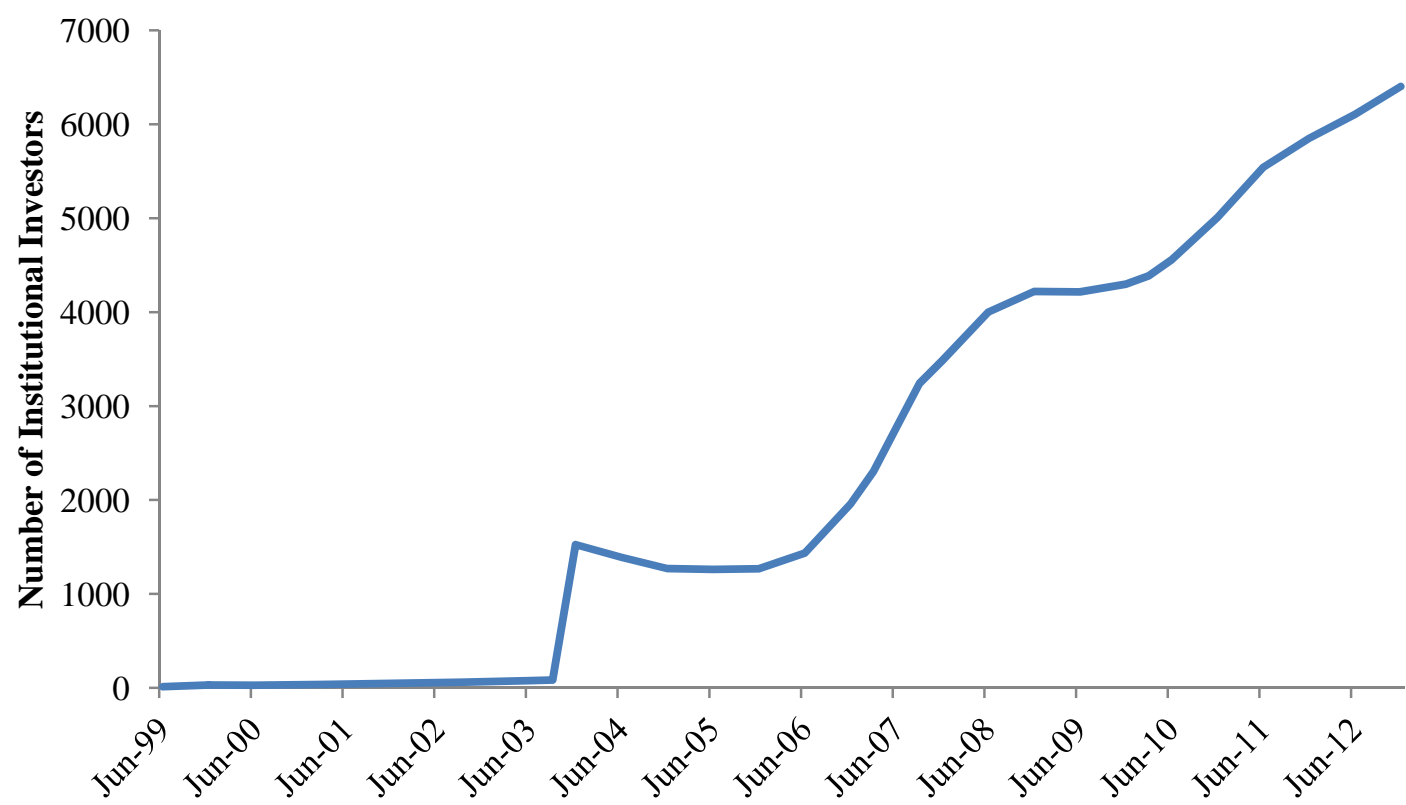

Fig 2b Share of Institutional Investor Holdings
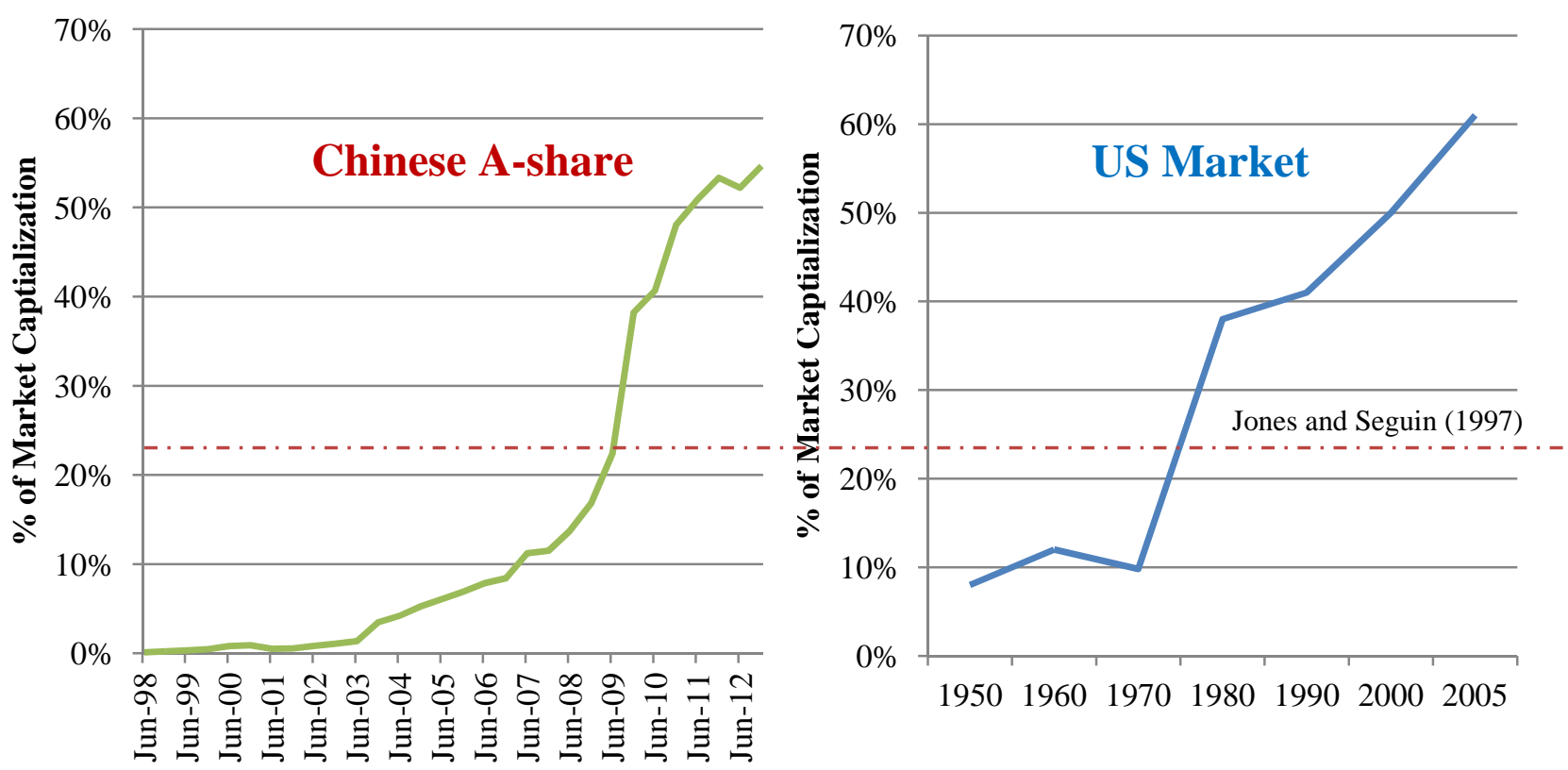
Figure 3: Institutional investors and their turnovers at the stock level

The figures below provide snapshots of institutional investor share in A-share market at stock level in 2000 and 2008 respectively. Fig 4a shows the average number of institutional investors at stock level at the end of Q4 in 2000 and 2008, while Fig 4b shows the institutional turnover at the stock level.

\section{Fig 3a Number of institutional investors at stock level}

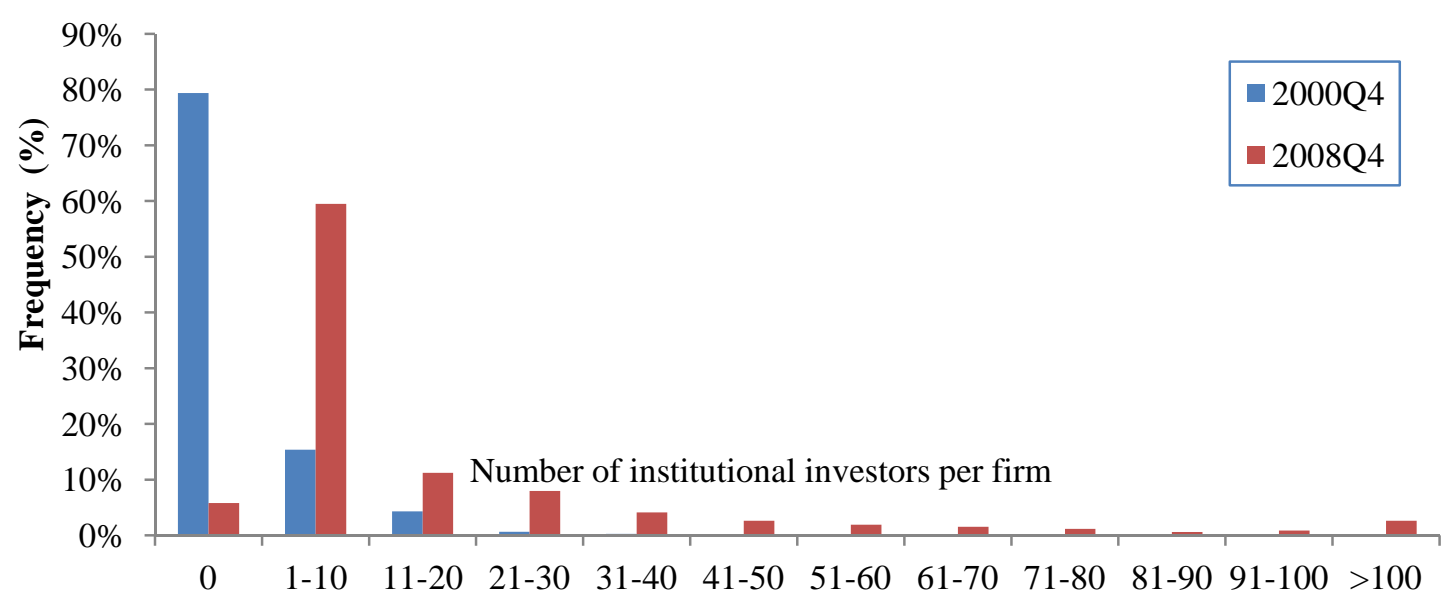

Fig 3b Institutional holding turnover at stock level

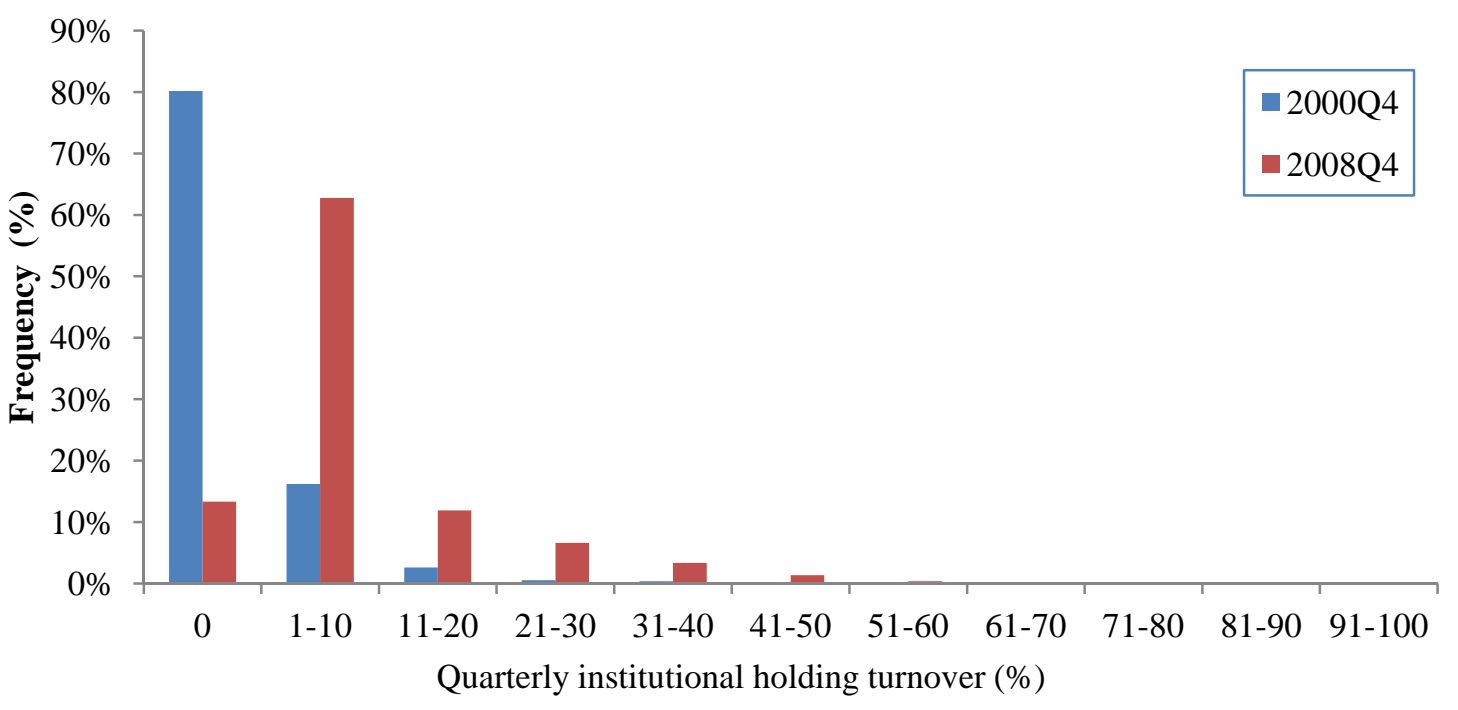


Figure 4: Scatter Plots of Price Volatility in the Two Markets

The Y-axis is the A-share price volatility averaged over the sample period, and the X-axis is the H-share price volatility averaged over the sample period.

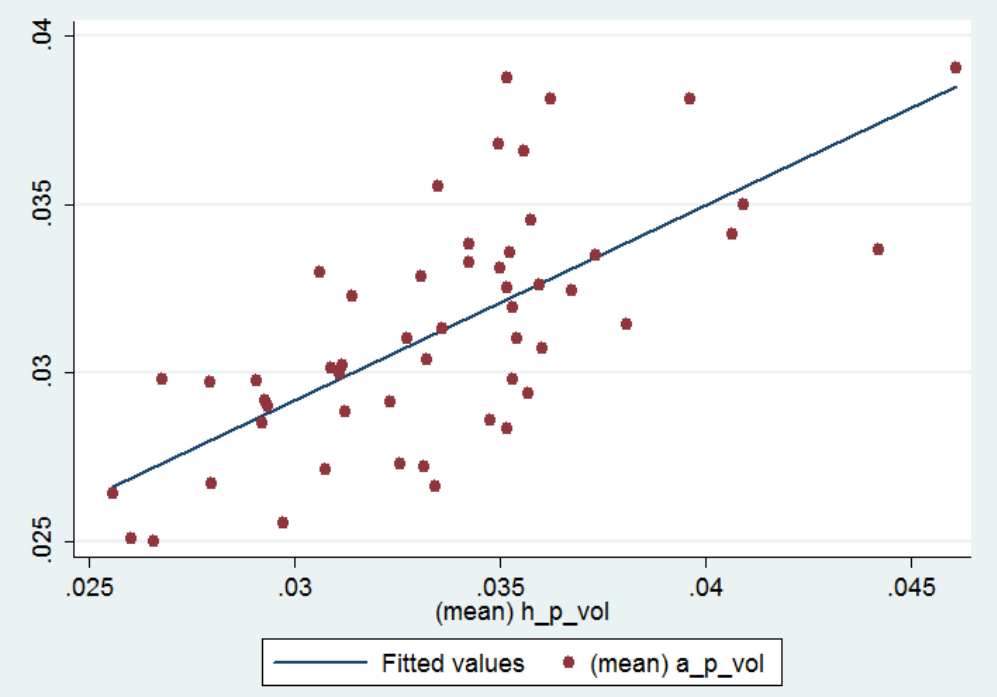


Figure 5: Changes in Relative Volatility by Event

Figure 5a shows the double difference in price volatility of treatment group (A-shares) against control group (H-shares) by event over 200 trading days before and after a. Double difference in price volatility is constructed as $\left(\text { Price_vol }_{\text {post }}-\text { Price_vol }_{\text {pre }}\right)_{A-\text { share }}-\left(\text { Price_vol }_{\text {post }}-\text { Price_vol }_{\text {pre }}\right)_{H-\text { share }}$. For event $\mathrm{m}$, unfitted price volatility is constructed followed Jones and Seguin (1997) as $\sqrt{\pi / 2} \times\left|R_{m, i, t}\right|$, where $R_{m, i, t}$ is the daily return of stock $\mathrm{i}$ and at day t. Figure $4 \mathrm{~b}$ shows the difference in fitted price volatility between $\mathrm{A}$ and $\mathrm{H}$ shares for each stamp duty event over 200 trading days before and after. $\left(\text { Price_vol }_{A-\text { share }} / \text { Price_vol }_{H-\text { share }}\right)_{\text {post }}-\left(\text { Price_vol }_{A-\text { share }} / \text { Price_vol }_{H-\text { share }}\right)_{\text {pre }}$. Fitted price volatility is the fitted value from a 12-lag auto regression of raw price volatility. X-axis represents the magnitude of the stamp duty adjustment, while $y$-axis represents the change in the relative price volatility.

\section{Fig 5a Double difference in price volatility (raw)}

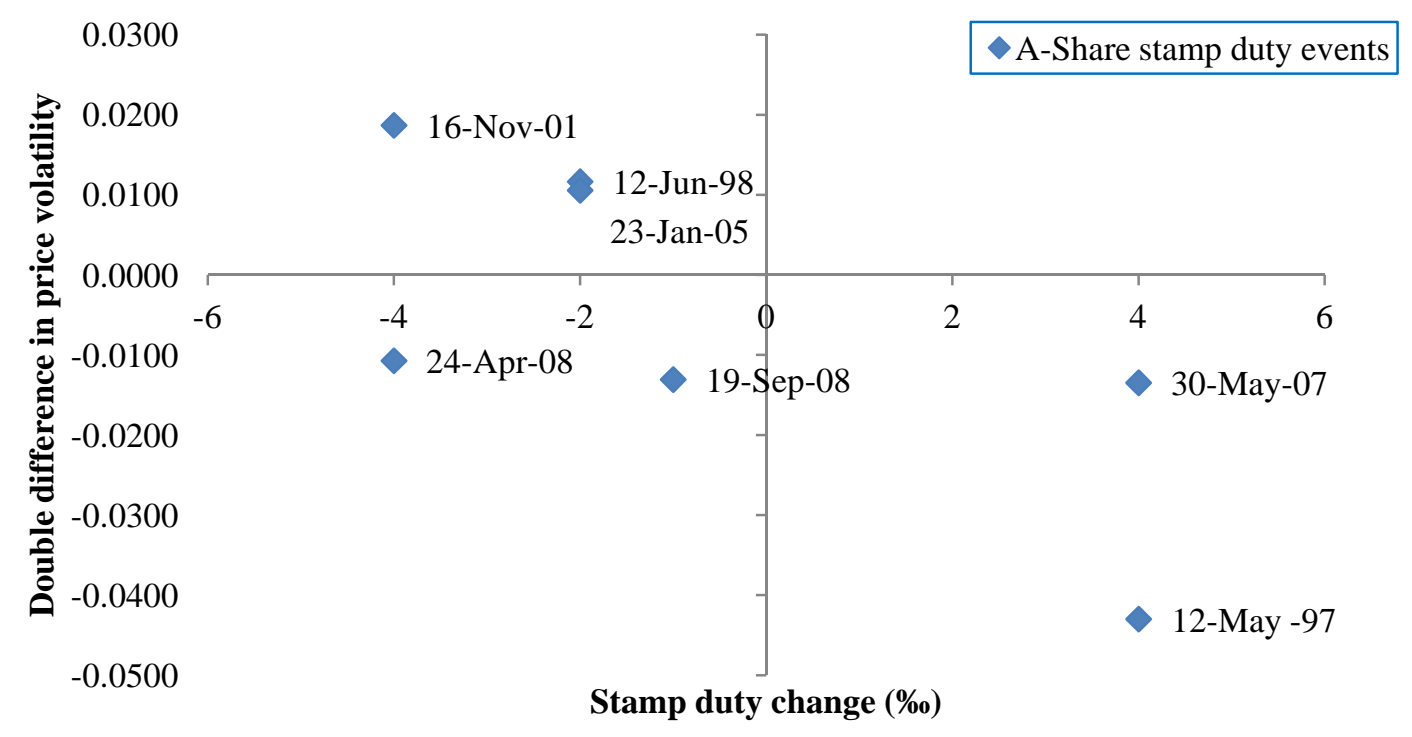

Fig 5b Difference in price volatility (A-share)/(H-share) (fitted)

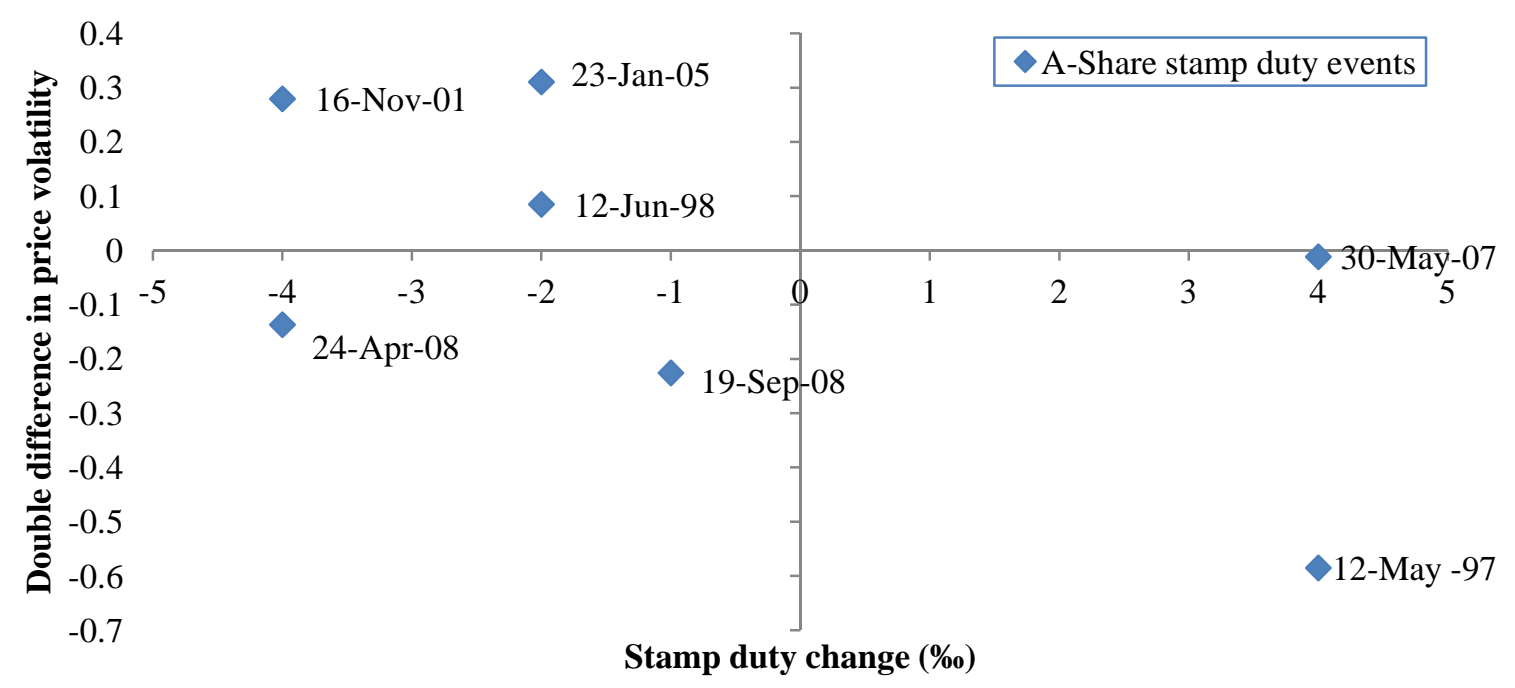


Figure 6: Effects of Stamp Duty on Price Volatility Depends on Institutional Investor Shares Graphical illustration of the estimated price volatility response to stamp duty changes as a function of institutional trading. Both results of OLS regression (columns 1-2 of Table 15) and 2SLS (columns 1-2 of Table 16) are plotted.

Fig 6a Institutional share turnover and the volatility response to higher tax

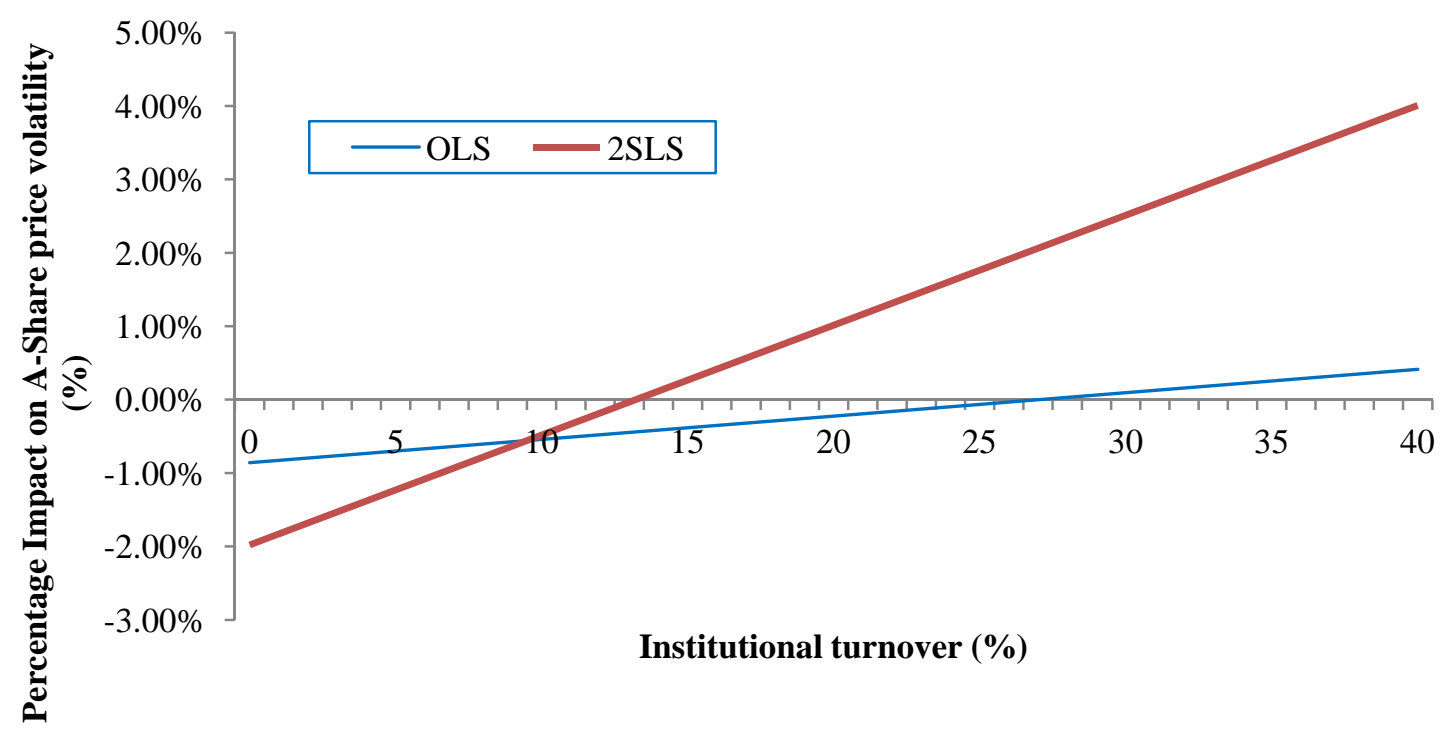

Fig 6b Number of institutional investors and volatility response to higher tax

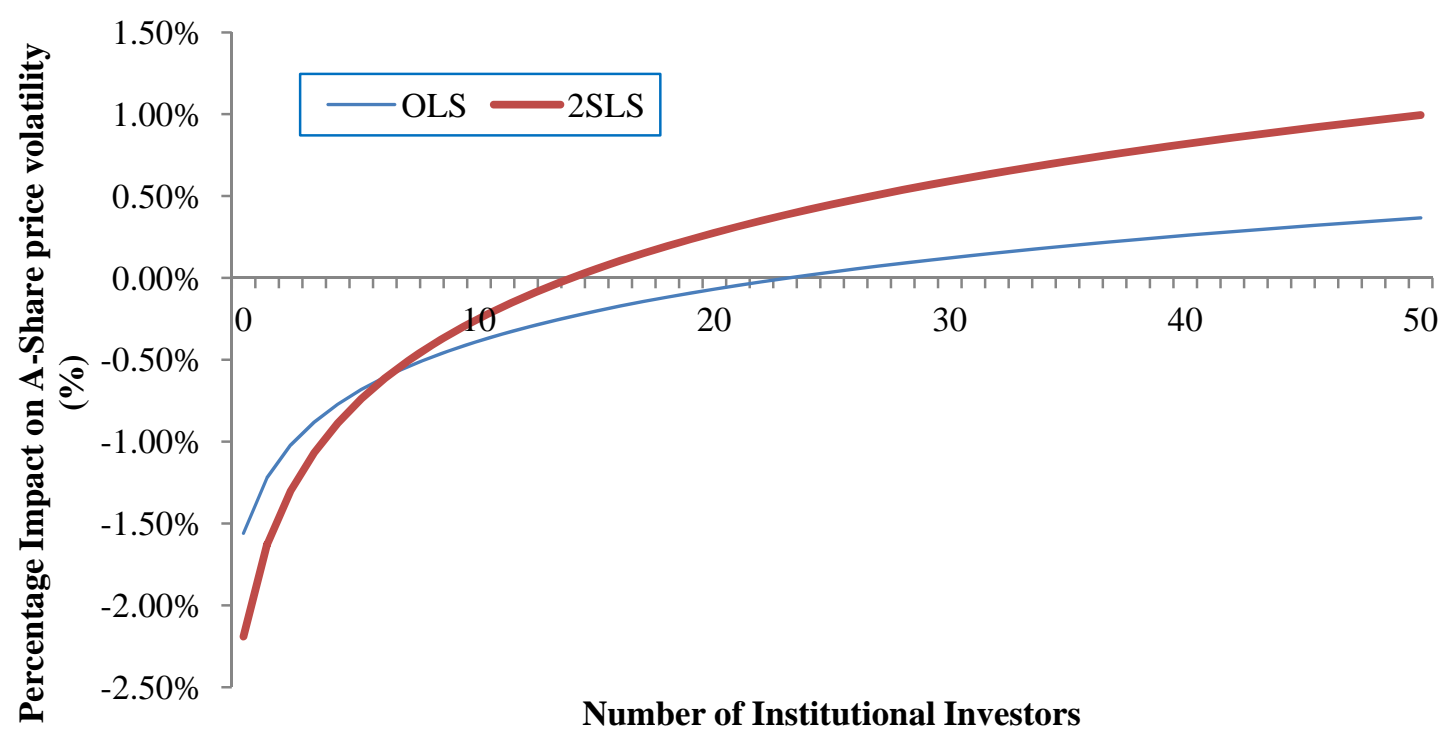




\section{Appendix 1: Sample Cross-Listed Stocks (for online publication only)}

Table below reports all 53 firms cross-listed in A-share and $\mathrm{H}$-share in our sample. The time for cross-listing is in boldface.

\begin{tabular}{|c|c|c|c|c|c|c|}
\hline No. & Name & Sector & H-Shares & $\begin{array}{c}\text { H-share IPO } \\
\text { date }\end{array}$ & A-Shares & $\begin{array}{c}\begin{array}{c}\text { A-share IPO } \\
\text { date }\end{array} \\
\end{array}$ \\
\hline 1 & Tsingtao Brewery Co Ltd & Beverages & $168 \mathrm{HK}$ & 7/15/1993 & $600600 \mathrm{CH}$ & 8/27/1993 \\
\hline 2 & Guangzhou Shipyard International & Machinery & $317 \mathrm{HK}$ & 8/6/1993 & $600685 \mathrm{CH}$ & 10/28/1993 \\
\hline 3 & Sinopec Shanghai Petrochemical & Chemicals & $338 \mathrm{HK}$ & 7/26/1993 & $600688 \mathrm{CH}$ & 11/8/1993 \\
\hline 4 & Shenji Group Kunming Machine & Machinery & $300 \mathrm{HK}$ & 12/7/1993 & $600806 \mathrm{CH}$ & $1 / 3 / 1994$ \\
\hline 5 & Maanshan Iron \& Steel & Metals \& Mining & $323 \mathrm{HK}$ & $11 / 3 / 1993$ & $600808 \mathrm{CH}$ & 1/6/1994 \\
\hline 6 & Beiren Printing Machinery & Machinery & $187 \mathrm{HK}$ & 8/6/1993 & $600860 \mathrm{CH}$ & $5 / 6 / 1994$ \\
\hline 7 & Tianjin Capital Environmental & Commercial Services \& Supplies & $1065 \mathrm{HK}$ & $5 / 17 / 1994$ & $600874 \mathrm{CH}$ & $5 / 17 / 1994$ \\
\hline 8 & Dongfang Electric Corp Ltd & Electrical Equipment & $1072 \mathrm{HK}$ & 6/6/1994 & $600875 \mathrm{CH}$ & 6/6/1994 \\
\hline 9 & Luoyang Glass Co Ltd & Building Products & $1108 \mathrm{HK}$ & 7/8/1994 & $600876 \mathrm{CH}$ & 7/8/1994 \\
\hline 10 & Sinopec Yizheng Chemical Fiber & Chemicals & $1033 \mathrm{HK}$ & 3/29/1994 & $600871 \mathrm{CH}$ & 4/11/1995 \\
\hline 11 & Northeast Electric Development & Electrical Equipment & $42 \mathrm{HK}$ & 7/5/1995 & $000585 \mathrm{CH}$ & 12/13/1995 \\
\hline 12 & Nanjing Panda Electronics Co L & Communications Equipment & $553 \mathrm{HK}$ & 4/24/1996 & $600775 \mathrm{CH}$ & 11/18/1996 \\
\hline 13 & Jingwei Textile Machinery & Machinery & $350 \mathrm{HK}$ & 2/2/1996 & $000666 \mathrm{CH}$ & $12 / 10 / 1996$ \\
\hline 14 & Shandong Xinhua Pharmaceutical & Pharmaceuticals & $719 \mathrm{HK}$ & 12/31/1996 & $000756 \mathrm{CH}$ & 8/6/1997 \\
\hline 15 & China Eastern Airlines Corp Lt & Airlines & $670 \mathrm{HK}$ & 2/5/1997 & $600115 \mathrm{CH}$ & 11/5/1997 \\
\hline 16 & Angang Steel Co Ltd & Metals \& Mining & $347 \mathrm{HK}$ & $7 / 24 / 1997$ & $000898 \mathrm{CH}$ & $12 / 25 / 1997$ \\
\hline 17 & Yanzhou Coal Mining Co Ltd & Oil, Gas \& Consumable Fuels & $1171 \mathrm{HK}$ & 4/1/1998 & $600188 \mathrm{CH}$ & 7/1/1998 \\
\hline 18 & Hisense Kelon Electrical Holding & Household Durables & $921 \mathrm{HK}$ & 7/23/1996 & $000921 \mathrm{CH}$ & 7/13/1999 \\
\hline 19 & Jiangsu Expressway Co Ltd & Transportation Infrastructure & $177 \mathrm{HK}$ & 6/27/1997 & $600377 \mathrm{CH}$ & $1 / 16 / 2001$ \\
\hline 20 & Guangzhou Pharmaceutical Co Lt & Pharmaceuticals & $874 \mathrm{HK}$ & 10/30/1997 & $600332 \mathrm{CH}$ & $2 / 6 / 2001$ \\
\hline 21 & China Petroleum \& Chemical Co & Oil, Gas \& Consumable Fuels & $386 \mathrm{HK}$ & $10 / 19 / 2000$ & $600028 \mathrm{CH}$ & $8 / 8 / 2001$ \\
\hline 22 & Huaneng Power International In & Independent Power Producers \& & $902 \mathrm{HK}$ & $1 / 21 / 1998$ & $600011 \mathrm{CH}$ & $12 / 6 / 2001$ \\
\hline 23 & Shenzhen Expressway Co Ltd & Transportation Infrastructure & $548 \mathrm{HK}$ & 3/12/1997 & $600548 \mathrm{CH}$ & $12 / 25 / 2001$ \\
\hline 24 & Jiangxi Copper Co Ltd & Metals \& Mining & $358 \mathrm{HK}$ & $6 / 12 / 1997$ & $600362 \mathrm{CH}$ & $1 / 11 / 2002$ \\
\hline 25 & Anhui Conch Cement Co Ltd & Construction Materials & $914 \mathrm{HK}$ & 10/21/1997 & $600585 \mathrm{CH}$ & $2 / 7 / 2002$ \\
\hline 26 & China Shipping Development Co & Marine & $1138 \mathrm{HK}$ & 11/11/1994 & $600026 \mathrm{CH}$ & $5 / 23 / 2002$ \\
\hline 27 & Anhui Expressway Co & Transportation Infrastructure & $995 \mathrm{HK}$ & $11 / 13 / 1996$ & $600012 \mathrm{CH}$ & 1/7/2003 \\
\hline
\end{tabular}




\begin{tabular}{|c|c|c|c|c|c|c|}
\hline 28 & China Southern Airlines Co Ltd & Airlines & $1055 \mathrm{HK}$ & 7/31/1997 & $600029 \mathrm{CH}$ & $7 / 25 / 2003$ \\
\hline 29 & ZTE Corp & Communications Equipment & $763 \mathrm{HK}$ & $12 / 9 / 2004$ & $000063 \mathrm{CH}$ & 11/18/1997 \\
\hline 30 & Huadian Power International Co & Independent Power Producers \& & $1071 \mathrm{HK}$ & 6/30/1999 & $600027 \mathrm{CH}$ & 2/3/2005 \\
\hline 31 & Bank of China Ltd & Commercial Banks & $3988 \mathrm{HK}$ & $6 / 1 / 2006$ & $601988 \mathrm{CH}$ & $7 / 5 / 2006$ \\
\hline 32 & Air China Ltd & Airlines & $753 \mathrm{HK}$ & $12 / 15 / 2004$ & $601111 \mathrm{CH}$ & 8/18/2006 \\
\hline 33 & China Merchants Bank Co Ltd & Commercial Banks & 3968 HK & 9/22/2006 & $600036 \mathrm{CH}$ & 4/9/2002 \\
\hline 34 & Beijing North Star Co Ltd & Real Estate Management \& Devel & $588 \mathrm{HK}$ & $5 / 14 / 1997$ & $601588 \mathrm{CH}$ & 10/16/2006 \\
\hline 35 & ICBC & Commercial Banks & $1398 \mathrm{HK}$ & $10 / 27 / 2006$ & $601398 \mathrm{CH}$ & $10 / 27 / 2006$ \\
\hline 36 & Datang International Power Generation Co Ltd & Independent Power Producers \& & $991 \mathrm{HK}$ & 3/21/1997 & $601991 \mathrm{CH}$ & $12 / 20 / 2006$ \\
\hline 37 & Guangshen Railway Co Ltd & Road \& Rail & $525 \mathrm{HK}$ & $5 / 14 / 1996$ & $601333 \mathrm{CH}$ & $12 / 22 / 2006$ \\
\hline 38 & China Life Insurance Co Ltd & Insurance & 2628 HK & $12 / 18 / 2003$ & $601628 \mathrm{CH}$ & 1/9/2007 \\
\hline 39 & Chongqing Iron \& Steel Co Ltd & Metals \& Mining & $1053 \mathrm{HK}$ & 10/17/1997 & $601005 \mathrm{CH}$ & 2/28/2007 \\
\hline 40 & Ping An Insurance Group Co of & Insurance & $2318 \mathrm{HK}$ & $6 / 24 / 2004$ & $601318 \mathrm{CH}$ & $3 / 1 / 2007$ \\
\hline 41 & China CITIC Bank Corp Ltd & Commercial Banks & $998 \mathrm{HK}$ & $4 / 27 / 2007$ & $601998 \mathrm{CH}$ & $4 / 27 / 2007$ \\
\hline 42 & Aluminum Corp of China Ltd & Metals \& Mining & $2600 \mathrm{HK}$ & $12 / 12 / 2001$ & $601600 \mathrm{CH}$ & 4/30/2007 \\
\hline 43 & Weichai Power Co Ltd & Machinery & 2338 HK & $3 / 11 / 2004$ & $000338 \mathrm{CH}$ & 4/30/2007 \\
\hline 44 & Bank of Communications Co Ltd & Commercial Banks & $3328 \mathrm{HK}$ & $6 / 23 / 2005$ & $601328 \mathrm{CH}$ & $5 / 15 / 2007$ \\
\hline 45 & China COSCO Holdings Co Ltd & Marine & 1919 HK & 6/30/2005 & $601919 \mathrm{CH}$ & 6/26/2007 \\
\hline 46 & China Construction Bank Corp & Commercial Banks & $939 \mathrm{HK}$ & $10 / 27 / 2005$ & $601939 \mathrm{CH}$ & 9/25/2007 \\
\hline 47 & China Oilfield Services Ltd & Energy Equipment \& Services & $2883 \mathrm{HK}$ & $11 / 20 / 2002$ & $601808 \mathrm{CH}$ & 9/28/2007 \\
\hline 48 & China Shenhua Energy Co Ltd & Oil, Gas \& Consumable Fuels & $1088 \mathrm{HK}$ & $6 / 15 / 2005$ & $601088 \mathrm{CH}$ & 10/9/2007 \\
\hline 49 & PetroChina Co Ltd & Oil, Gas \& Consumable Fuels & $857 \mathrm{HK}$ & $4 / 7 / 2000$ & $601857 \mathrm{CH}$ & $11 / 5 / 2007$ \\
\hline 50 & China Railway Group Ltd & Construction \& Engineering & $390 \mathrm{HK}$ & $12 / 7 / 2007$ & $601390 \mathrm{CH}$ & $12 / 3 / 2007$ \\
\hline 51 & China Shipping Container Lines & Marine & $2866 \mathrm{HK}$ & $6 / 16 / 2004$ & $601866 \mathrm{CH}$ & $12 / 12 / 2007$ \\
\hline 52 & China Coal Energy Co Ltd & Oil, Gas \& Consumable Fuels & $1898 \mathrm{HK}$ & $12 / 19 / 2006$ & $601898 \mathrm{CH}$ & $2 / 1 / 2008$ \\
\hline 53 & China Railway Construction Cor & Construction \& Engineering & $1186 \mathrm{HK}$ & 3/13/2008 & $601186 \mathrm{CH}$ & 3/10/2008 \\
\hline
\end{tabular}


Appendix 2: Definition of Variable (to be published online only)

\section{Variable \\ Key variable \\ Return}

Share turnover

Price volatility (unfitted)

Price volatility (fitted)

Higher tax dummy

\section{Control variables}

Size of stamp duty change

Initial level of stamp duty

Difference in interest rate (China-HK)

Institutional share variables

Institutional ownership

Institutional turnover

Ln(Number of institutional investors)

\section{Instruments}

CSI 300 member dummy

Ln(asset)

Amihud illiquidity ratio
Definition

Daily returns of $\mathrm{A}$ and $\mathrm{H}$ shares are obtained directly from databases including CSMAR, PACAP, and Datastream.

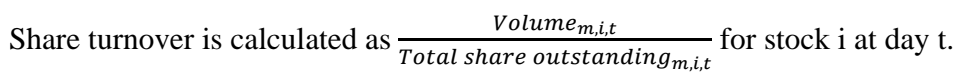

Unfitted price volatility is calculated as $\sqrt{\frac{\pi}{2}}\left|R_{m, t}\right|$ for event $\mathrm{m}$ and day $\mathrm{t}$ as Jones and Seguin (1997).

Fitted price volatility is the predicted value of $\sigma_{i t}=\sum_{n=1}^{12} \sigma_{i, t-n}+\varepsilon_{t}$, where $\sigma_{i t}$ is the unsigned daily stock return scaled by $\sqrt{\pi / 2}$ as Jones and Seguin (1997).

Higher tax dummy equals to 1 if the day t is in the higher stamp duty time period and zero otherwise.

Absolute value of change in certain stamp duty change. (unit: \%o)

Initial level of stamp duty prior to a certain stamp duty change. (unit: \%o)

The variable is calculated as (12-month base interest rate (China) - 12-month base interest rate (HK)) on monthly basis. (unit: \%)

Obtained from WIND databases and reflects the latest quarter filing prior to a certain stamp duty change

The sum of absolute value of change in ownership of each institutional investor for sample A-share in the latest quarter prior to each stamp duty change. Obtained from WIND database with unit of $\%$.

Ln(number of outstanding institutional investors +1 ) in A-share stocks a quarter prior to stamp duty changes. Obtained from WIND database.

Dummy variable equals to 1 if a sample A-share is a member of the CSI 300 index at the time of a certain stamp duty change, and zero otherwise

Natural logarithm of total asset obtained from CSMAR in the latest annual filing prior to each stamp duty change.

Illiquidity ratio is calculated as $I L L I Q_{i, y}=\frac{1}{\operatorname{Days}_{i, y}} \sum_{d=1}^{\text {Days }_{i, y}} \frac{\left|R_{i, y, d}\right|}{\operatorname{DVol}_{i, y, d}}$, where Days $_{i, y}$ is the number of valid observation days in year $\mathrm{y}, R_{i, y, d}$ and $D V o l_{i, y, d}$ are the daily return and dollar volume of stock I on day d of year $\mathrm{y}$. The ratio is rescaled by a factor of $10^{6}$

Potential outlier stocks

Potential outliers refer to stock observations with price (A-share)/price(Hshare) above $99^{\text {th }}, 95^{\text {th }}$ and $90^{\text {th }}$ percentiles. 